DOI: 10.1002/adsc.201((will be filled in by the editorial staff))

\title{
Cyclisation Reactions Involving Alkyl Enol Ethers
}

\section{Luisa Lempenauer, ${ }^{a}$ Gilles Lemière ${ }^{\mathrm{b} *}$ and Elisabet Duñach ${ }^{\mathrm{a} *}$}

a Université Côte d'Azur, CNRS, Institut de Chimie de Nice UMR 7272, Parc Valrose, 06108 Nice Cedex 2, France E-mail: dunach@unice.fr

b Sorbonne Université, CNRS, Institut Parisien de Chimie Moléculaire, 4 Place Jussieu, CC 229, 75252 Paris Cedex 05 (France), E-mail: gilles.lemiere@sorbonne-universite.fr

Received: ((will be filled in by the editorial staff))

\begin{abstract}
Enol ethers are a fascinating product class and valuable building blocks with versatile reactivities and synthetic applications. With the emergence of silyl enol ethers, the chemistry of simple alkyl enol ethers has received less attention and targeted reviews of their chemistry are scarce. Especially intramolecular reactions under participation of an enol ether function have never been specifically surveyed. The construction of cyclic scaffolds is arguably one of the most important and challenging tasks of the organic chemist and intramolecular cyclisations represent the most straight-forward tool to achieve this goal. The potential of enol ether-containing substrates to form oxygenated carbo- and heterocycles is obvious. The purpose of this review is to discuss their particular reactivity and to bring to the reader's attention how their unique properties have been harnessed by organic chemists for the construction of rings.
\end{abstract}

\section{Introduction}

Oxygenated carbo- and heterocycles are an important class of organic compounds with manifold functions in diverse biological processes. ${ }^{[1]}$ In this regard, the assembly of complex (poly)cyclic scaffolds from easily accessible precursors is an important area of research in organic synthesis and there still is a growing need for the development of more selective and efficient synthetic means. The implementation of new catalytic methodologies for the construction of cyclic scaffolds by electrophilic activation of (poly)unsaturated precursors has been a longstanding interest of the community and intramolecular cyclisations continue to provide efficient and atomeconomic tools for carbo- and heterocycle synthesis. ${ }^{[2]}$ While cyclisations and cycloisomerisations of dienes and enynes are well documented, ${ }^{[3]}$ the introduction of oxygen-functionality into the precursor molecules by means of an enol ether is less explored. Since enol ethers can be considered reactive derivatives of ketones or aldehydes, as well as activated, electron-rich alkenes, they often share common reactivity patterns with their parent structures and undergo similar chemical transformations. In the scientific literature, enol ethers therefore often appear marginally, as "exotic" examples, when reactions of olefins or carbonyl compounds are discussed. The only systematic review

\section{Abstract Text----Continued}

Keywords: enol ethers; cyclisations; catalysis; Lewis acid; intramolecular reactions describing the reactivity and applications of alkyl enol ethers in organic reactions dates back to 1968 and merely covers direct functionalisations at the $\beta$ carbon by external electrophiles. ${ }^{[4]}$ Other available reviews focus on the reactions of functionalised alkoxyethylenes bearing electron-withdrawing groups ${ }^{[5]}$ as well as silyl enol ethers, which have received considerably more attention, due to their remarkable synthetic usefulness, versatility of application and clean reactions. ${ }^{[6]}$

This review is aimed at providing a concise overview of Lewis and Brønsted acid-catalyzed intramolecular ring-forming reactions through $\mathrm{C}-\mathrm{C}$ bond formation involving alkyl enol ethers, which in their majority follow cationic-type mechanisms. Some exceptions from acid-catalysis are included due to particular elegance of the transformation. Even though silyl enol ethers have been employed in a multitude of cyclisation procedures, ${ }^{[7]}$ they will not be discussed within the scope of this survey. Cyclisations of chemically generated radical cations will as well be excluded. Oxidative cyclisations of electrochemically generated enol ether radical cations have been developed essentially by the Moeller group over the last 30 years. ${ }^{[8]}$ Likewise, this chemistry has been reviewed and is therefore not included herein. 
Luisa Lempenauer received her $M$. Sc. degree in chemistry from the Technical University of Munich, Germany, in 2014. After several research placements at the $T U$ Munich and the King Abdullah University of Science and Technology (Saudi-Arabia), she joined the group of Elisabet Duñach at the Insitut de Chimie de Nice in 2015 to pursue her PhD studies on novel catalytic

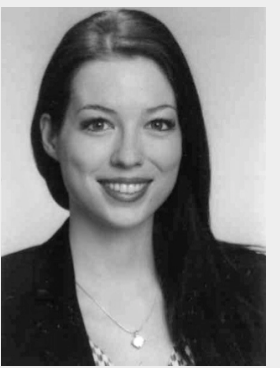
cyclisation and cycloisomerisation reactions. Luisa's research interests focus on the development of scalable and sustainable catalytic methods for the synthesis of novel compounds with applications in the flavour and fragrance industry.

Gilles Lemière studied chemistry in Paris at the Universite Pierre et Marie Curie (UPMC), where he obtained his PhD in 2008 under the supervision of Profs. Louis Fensterbank and Max Malacria. After his PhD on gold-catalysed new organic reactions, he joined the group of Prof. Jonathan Clayden in Manchester as a postdoctoral fellow to work on the total synthesis of natural compounds. In 2010, he was appointed CNRS Researcher in the team of Dr. Elisabet Duñach at the University of Nice, where he worked on the design of new metal-and acid-catalysed cycloisomerisation processes. In 2015, he moved to the Institut Parisien de Chimie Moléculaire at the Sorbonne Université, Paris.

Elisabet Duñach was born in Barcelona, Spain. She obtained her PhD at the University of Barcelona in 1981 in the group of J. Castells. After postdoctoral research at the University of California, Berkeley (K. Vollhardt, $1981-1983)$ and at the University Paris XI, Orsay (H. Kagan, 1983 - 1985), she became $C N R S$ researcher in the group of $J$. Périchon in 1985. In 1991 she joined the Laboratoire de Chimie

Moléculaire at the University of Nice. She is now Director of Research at the CNRS and has been the director of the Institut de Chimie de Nice. Her interests involve the development of new catalytic methodologies in organic synthesis, as well as applications in the field of flavours and fragrances.

\section{General aspects}

Enol ethers are a product class frequently used in organic synthesis. ${ }^{[9]}$ Their ability to react with both nucleophiles and electrophiles, depending on the substrate and the reaction conditions, contributes to the versatility of their chemistry. Their reactivity towards electrophiles is characterised by the enhanced electron density at the $\beta$-C atom, due to the participation of the mesomeric oxonium form 2 (Scheme 1).

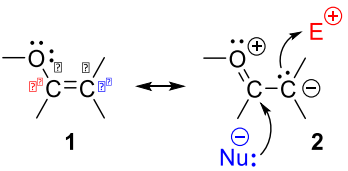

Scheme 1. General structure of the enol ether function and its mesomeric zwitterionic oxonium form.

On the other hand, the electron-deficient character of the $\alpha$-C atom is reflected in the pronounced tendency to react with nucleophiles, especially under acidic conditions, where protonation at the $\beta$-position may lead to the formation of a highly reactive oxocarbenium species. In that manner, the enol ether can be understood as a sort of pro-electrophile, as the reactivity towards nucleophiles is triggered by its inherently nucleophilic character. ${ }^{1} \mathrm{H}-$ and ${ }^{13} \mathrm{C}$-NMR studies on different aliphatic alkyl enol ethers have revealed that their reactivity in cationic-type reactions directly correlates with the electron-donating power as well as with the steric bulk of the alkyl group attached to the oxygen. ${ }^{[10]}$ An increasing electrondonating character of the O-alkyl substituent will augment the electron-density at the $\alpha$-carbon, while the contribution to the zwitterionic resonance structure will lead to an increased electron-density at the $\beta$-carbon. The degree of resonance contribution in alkyl enol ethers is thought to be dependent on the conformation of the enol ether. Given an essential $s p^{3}$-hybridisation of the oxygen atom, the conformers shown in Figure 1 can be considered.
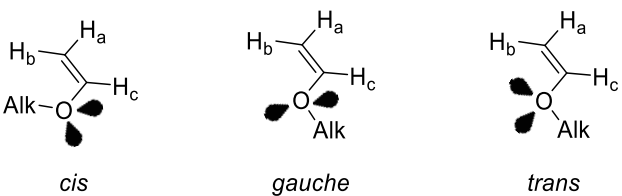

gauche

trans

Figure 1. Different conformations of alkyl enol ethers.

Among them, the cis and the trans forms are the most suitable for resonance, due to a favorable overlap of the olefinic $\pi$-orbitals and the $p$-orbitals of the oxygen lone-pairs, while resonance is hindered in the gauche conformation. The contribution of the gauche form increases with the steric bulk of the alkyl group, while the cis and the trans forms become proportionally less populated due to unfavorable steric interaction between the alkyl group and the vinylic protons $\left(\mathrm{H}_{\mathrm{a}}\right.$ or $\left.\mathrm{H}_{\mathrm{b}}\right)$. The resulting lack of resonance stabilisation confers a higher reactivity to enol ethers bearing a sterically demanding $O$-alkyl group. Thus, the reactivity of enol ethers in cationictype reactions is mainly governed by steric effects, tert-butyl vinyl ether being more reactive towards cationic polymerisation than ethyl vinyl ether. 
A series of investigations dedicated to understanding the behavior of alkoxy-substituted olefins in electrophilic additions and nucleophilicity scales of alkyl enol ethers and related vinyl nucleophiles based on different methods are available. For example, a nucleophilicity scale based on the reaction of vinyl compounds with benzhydryl cations has been established. ${ }^{[11]}$ Enol ethers are more nucleophilic than simple alkyl-substituted ethylenes by five orders of magnitude and their nucleophilicities are in the same range as those of allyl silanes, water, alcohols and some silyl enol ethers. The bulkyness of the $O$-alkyl group was again found to have a considerable influence on the reactivity of the enol ether and thus tert-butyl vinyl ether was 2.5 times more nucleophilic than ethyl vinyl ether. Alkyl-substitution of the vinylic protons enhances the nucleophilicity, while the effect is more pronounced in the case of $\beta$ substituents. In the cyclic series, a higher nucleophilicity of five-membered as compared to sixmembered ring enol ethers has been stated and accordingly, dihydrofuran is often found to be more reactive than dihydropyran in reactions with electrophiles. ${ }^{[12]}$ Interestingly, while the rate constants of electrophilic additions to alkenes strongly depend on the stabilities of the formed carbenium ions, it was found that the stabilities of the carbenium ions produced in the addition step are of minor importance in the case of enol ethers, where a good correlation between reactivity and ionisation potentials was instead observed. This is in agreement with high rates and early transition states in reactions of enol ethers as compared to slower reactions with late transition states in the case of alkenes. ${ }^{[11 b]}$

\section{Lewis and Bronsted acid-catalysed cyclisations and cycloisomerisations}

Proton transfer to carbon is a major catalytic challenge, since it is generally afflicted with considerable intrinsic energy barriers and often unfavorable thermodynamics. ${ }^{[13]}$ Enol ethers, however, are readily hydrolysed in dilute acid and the reactivity towards acid-catalysed hydrolysis follows the same trend as outlined above, the reactivity increasing with increasing steric bulk of the $O$-alkyl group. This seems somewhat contradictory, since a decreased electron-density at the $\beta$-carbon seems to be associated with a higher reactivity towards hydrolysis. It has therefore been evoked in early studies that protonation of the enol ether $\beta$-carbon cannot be the rate-limiting step in this reaction and that the increased electron-density at the $\alpha$-carbon is of importance. ${ }^{[10 \mathrm{~b}]}$ On the other hand, transition state analysis of the acid-catalysed hydrolysis of a biologically relevant enol ether revealed an irreversible and rate-determining nature of the proton transfer to the $\beta$-carbon with the formation of an oxocarbenium ion intermediate. ${ }^{[14]}$

The reactivity of enol ethers under acidic conditions is often delicate and difficult to control due to competitive polymerisation, in particular in the presence of Lewis acids. ${ }^{[15]}$ However, both Brønsted and Lewis acid-catalysed cyclisations involving enol ethers have been described. In most cases, initial protonation of the enol ether in the $\beta$-position leads to an oxonium species $\left(\mathbf{3} / \mathbf{3}^{\prime}\right)$ with an electrophilic $\alpha$ carbon, which is subsequently intercepted by a nucleophile (Scheme 2).

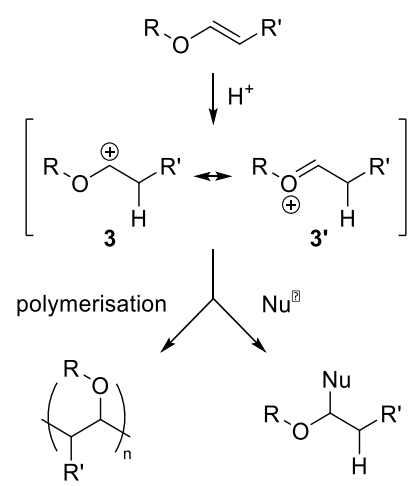

Scheme 2. Reactivity of enol ethers under acidic conditions.

When considered electron-rich alkenes, the ambiguous reactivity of enol ethers often makes their behavior towards metal catalysts difficult to assess in the presence of other susceptible functional groups within the same molecule and reports of their participation in catalytic cyclisation reactions therefore remain scarce.

\subsection{Reactivity as the electrophilic reaction partner}

\section{a) Acetal formation}

The protection of alcohols by conversion into their tetrahydropyranyl ethers is the most frequently used acid-catalysed reaction of an enol ether. Numerous acids or acid-precursors have been reported to promote this transformation (Scheme 3 ).

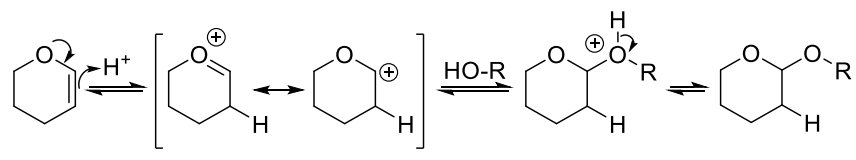

Scheme 3. Protection of an alcohol with dihydropyran under acidic conditions.

Protonation of the enol ether generates a reactive oxonium species which undergoes addition of the hydroxyl group. The formed acetal is stable towards basic, oxidizing and free radical conditions as well as organolithium and certain other nucleophilic reagents. ${ }^{[16]}$ For example, the intramolecular ketalisa- 
tion of an enol ether was applied as the last step of the total synthesis of the cephalotaxus alkaloid (-)drupacine (Scheme 4). ${ }^{[17]}$
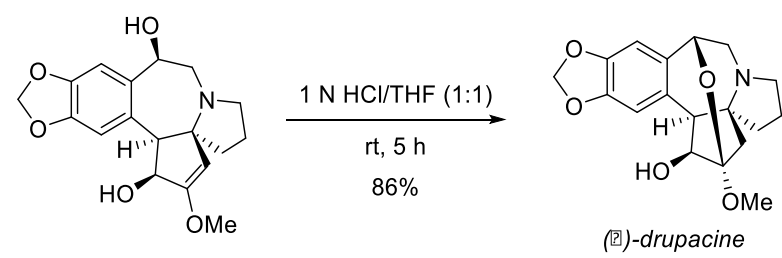

Scheme 4. Acid-catalysed intramolecular ketalisation in the total synthesis of (-)-drupacine.

Under mildly acidic conditions, the benzylic hydroxyl group underwent acetal linkage with the enol ether, leading to the oxygen-bridged polycyclic scaffold in $86 \%$ yield.

\section{b) Cyclisations of enol ethers with olefins and allenes}

The Lewis acid-catalysed cationic cycloisomerisation of an enol ether was studied as a key step in synthetic work towards important intermediates in the eudesmane series. ${ }^{[18]}$ Coordina-tion of the Lewis acid to the enol ether in $\mathbf{4}$ was not the initiating step, but the interaction occurred at the bridge-oxygen, promoting a tandem ring-opening cationic cyclisation sequence under nucleophilic attack of the tethered olefin on the intermediate oxocarbenium 5 (Scheme $5)$. Allylic proton elimination from 6 with concomitant 1,3-migration of the methoxy group to the peripheral alkyl chain then delivered the eudesmane skeleton of 7 .

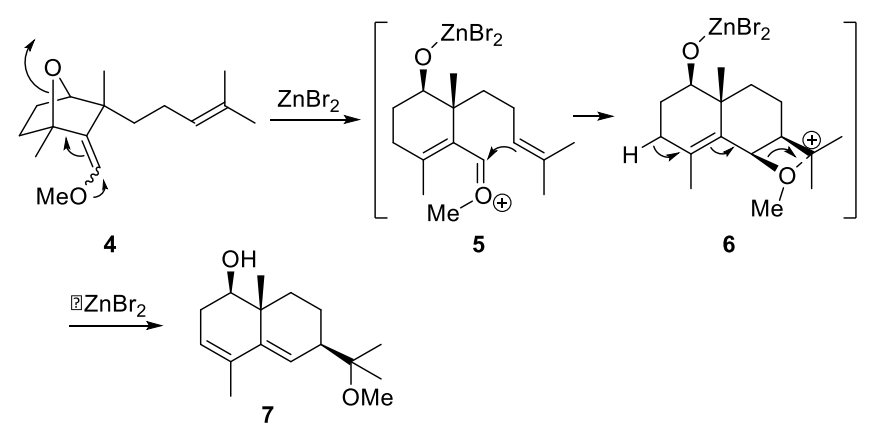

Scheme 5. Cationic oxonium-ene cyclisation towards the eudesmane skeleton.

Enol ethers have received considerable attention as reactive carbonyl derivatives in Prins-type reactions with appended olefins for the diastereoselective synthesis of tetrahydropyrans by cycloisomerisation. In the classical Prins-cyclisation, a two-component reaction between a carbonyl compound and an homoallylic alcohol under Lewis acidic conditions serves to generate the intermediate oxocarbenium species, which undergoes cyclisation to form either hydroxy tetrahydropyrans or dihydropyrans according to the reaction conditions (Scheme 6). ${ }^{[19]}$

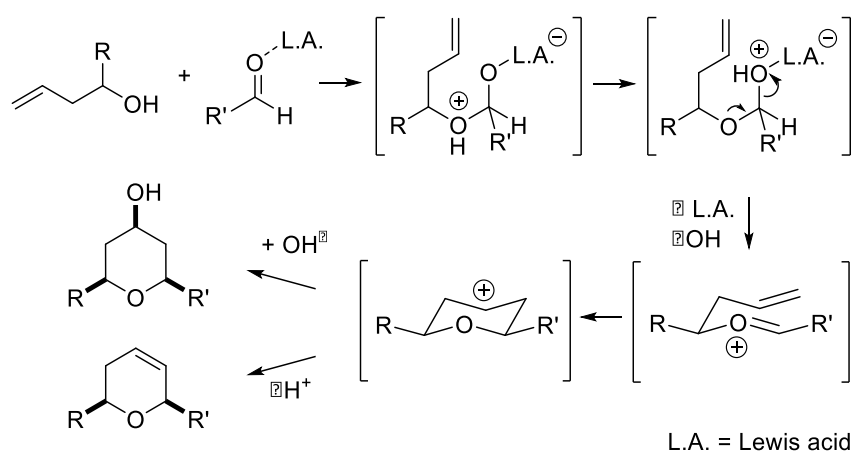

Scheme 6. The classical Prins cyclisation between an aldehyde an homoallylic alcohol.

The first intramolecular Prins-cyclisation involving an activated, electron-deficient enol ether has been introduced by Nussbaumer and Fráter ${ }^{[20]}$ in the context of the total synthesis of the floral odorant $( \pm)$ cis- $\alpha$-irone (Scheme 7).

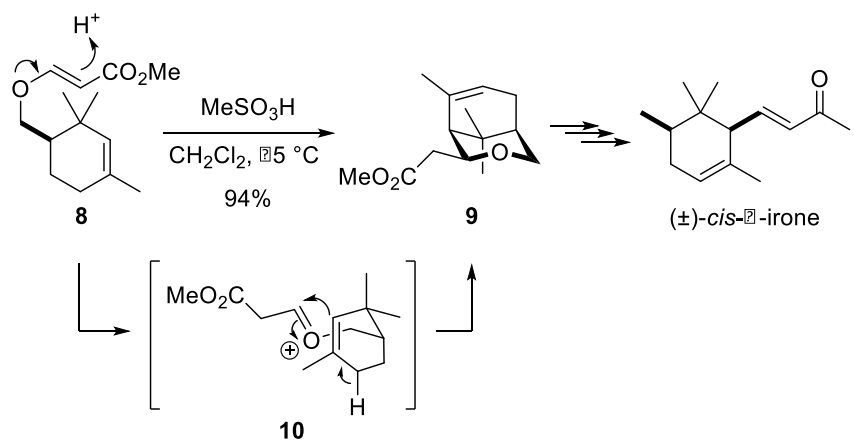

Scheme 7. Intramolecular Prins-type cyclisation of an acceptor-substituted enol ether.

The cyclisation of $\mathbf{8}$ was promoted by a slightly substoichiometric amount of methanesulfonic acid and proceeded with a high degree of diastereoselectivity to give the depicted 3-oxabicyclo[3.3.1] nonene derivative 9 with the cis-relationship of the substituents, exclusively. The authors propose a chair-like transition state where the carbomethoxymethyl group occupies an equatorial position to account for the diastereoselectivity of the 6-endo-trig cyclisation towards the key precursor of the natural product. In such a conformation, 1,3-diaxial interactions are minimal. The simultaneous shift of the ring double bond occurs via proton elimination from the resulting carbenium ion $\mathbf{1 0}$ and affords the neutral bicyclic compound 9 . Three more steps were then necessary to obtain the natural orris odorant. 
This type of cyclisation was used by the same group for the stereoselective synthesis of cis-( \pm civet. $^{[21]}$ This carboxylic acid is a constituent of the glandular secretion of the civet cat, which is valued in perfumery for its musky odor. ${ }^{[22]}$ Excess trifluoroacetic acid (TFA) promotes the cyclisation of $\mathbf{1 1}$ to give the substituted tetrahydropyran $\mathbf{1 2}$ after addition of water with the cis-configuration between $\mathrm{C} 2$ and C6 (Scheme 8).

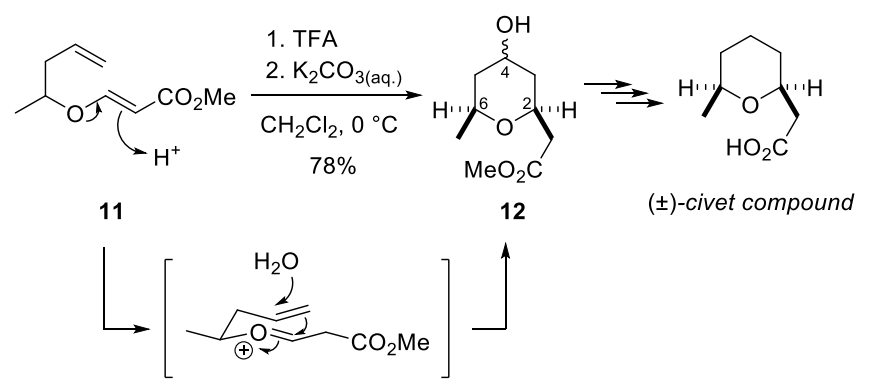

Scheme 8. Enol ether Prins-cyclisation in the total synthesis of $( \pm)$-civet.

Hydrolysis of the resulting secondary carbocation (or trifluoroacetate adduct) at the C4-position affords a 4hydroxy-tetrahydrofuran $\mathbf{1 2}$ as a mixture of diastereomers. Hereby, the all-cis compound is the major isomer, which corresponds to a preferred antiaddition of $\mathrm{H}_{2} \mathrm{O}$ across the terminal double bond. These reports represent the first examples employing enol ethers as the starter units in cationic olefin cyclisations. The scope and the mechanism of this highly diastereoselective alkoxyacrylate cyclisation, hitherto applied only to individual target-oriented syntheses, ${ }^{[2,21,23]}$ were later explored with respect to a more versatile preparation of substituted 4-hydroxy tetrahydropyrans. ${ }^{[24]}$ The reaction outcome was shown to be dependent on the cyclisation promoter and may be complicated by formal hydrolysis of the oxonium intermediate and by the formation of crossover products through sigmatropic rearrangements of the enol ether substrates. When strong Lewis acids are used $\left(\mathrm{TiCl}_{4}, \mathrm{TiBr}_{4}\right.$ and $\left.\mathrm{SnBr}_{4}\right)$, both yields and diastereoselectivities decreased and halogenation occurred at the $\mathrm{C} 4$ position. The authors suggest that a different mechanism via complexation of the Lewis acid to the ester group may operate in these cases. Other metal halogenides were tested and gave similar results. ${ }^{[25]}$ The presence of small amounts of water in the reaction medium were found to be crucial, probably with respect to a hydrolysisinduced Brønsted acidity of the metal chlorides delivering $\mathrm{HCl}$. The nature of the C6-substituent was further found to impact the degree of diastereoselectivity: stereochemical erosion was observed in the case of oxygen-containing groups. ${ }^{[24,25]}$ The effect of substituents in the alkenyloxy unit was also studied by Fráter et al. and shown to have an influence on the relative configuration of the cyclisation products. ${ }^{[26]}$ It has also been suggested, that protonation of the carbonyl oxygen of the ester group for the generation of the incipient oxocarbenium ion might be more likely than a direct protonation of the enol ether. ${ }^{[26]}$ More detailed studies on substituent effects on the regio- and stereochemical course of the reaction appeared shortly after this report. ${ }^{[27]}$

As already suggested by Nussbaumer et al.,$^{[21]}$ the use of enantiopure homoallylic alcohol $(S)$-13 as the precursors towards the enoxyester substrate $\mathbf{1 4}$ allowed for the asymmetric synthesis of $(+)$-civet (Scheme 9).

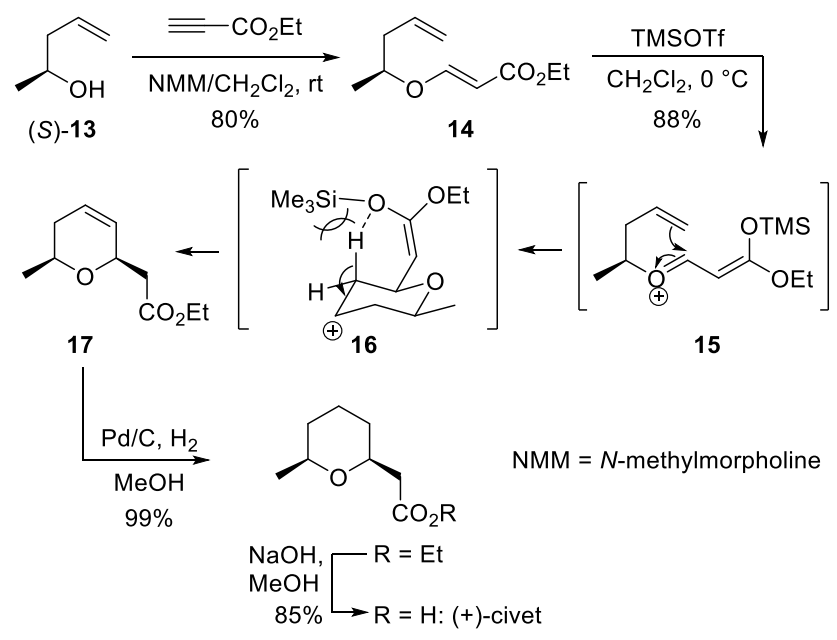

Scheme 9. Asymmetric synthesis of (+)-civet by $\beta$ alkoxyacrylate cyclisation.

The reported protocol employed overstoichiometric amounts of TMSOTf as the electrophilic promoter and represents a shorter version of the Nussbaumersynthesis, because it obviates the need for removal of the 4-hydroxyl group. It is noteworthy that only one regioisomeric product with respect to the location of the double bond in $\mathbf{1 7}$ is formed. The authors explain this fact by steric strain in the transition state $\mathbf{1 6}$ involving the bulky silyl group, which leads to a regioselective proton elimination assisted by the latter.

The inherent stereospecificity of the oxonium-ene cyclisation involving enol ethers has made it an attractive method for the stereocontrolled assembly of substituted oxygen-heterocycles and it has seen ample application in the total synthesis of natural products containing the tetrahydropyran motive. ${ }^{[29]}$ For example, the construction of the central tetrahydropyran unit of the marine metabolite clavosolide D was achieved by an enol ether Prinscyclisation and again demonstrated the usefulness of this approach for the concomitant introduction of three additional stereogenic centers with excellent stereocontrol (Scheme 10). ${ }^{[29 b]}$ 


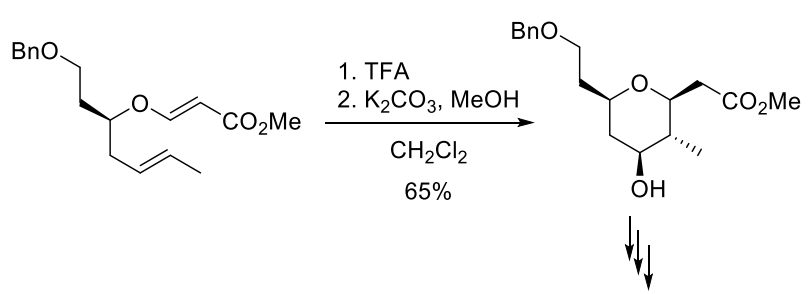

(回)-clavosolide D

Scheme 10. The enol ether Prins-cyclisation as a key-step in the total synthesis of (-)-clavosolide D.

The first catalytic version of the oxonium-ene Prinscyclisation has been devised by Puglisi et al. and employed unsubstituted enol ethers instead of deactivated alkoxyacrylates. ${ }^{[30]}$ Triflic acid at a concentration of $0.01 \mathrm{~mol} \%$ was found to efficiently catalyse the oxonium-ene cyclisation of unsubstituted vinyl ethers (Scheme 11).
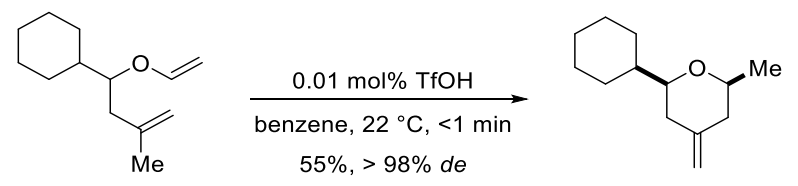

Scheme 11. Catalytic Prins-cyclisation of an unsubstituted enol ether.

Yields were generally good and the corresponding 4methylene tetrahydropyrans were obtained with excellent diastereoselectivities. The regioselectivity of proton elimination increased with decreasing catalyst loading and was also dependent on the substituents present on the starting enol ether. Unsubstituted vinyl ethers gave the best results, while substituents present on the $\alpha$ - or $\beta$-carbon decreased both yields and regioselectivities. The sterically hindered, electron-deficient alkoxyacrylates used in the pioneering studies gave rather poor results in this series.

Even though the majority of these cyclisations led to the formation of six-membered rings, the synthesis of substituted tetrahydrofurans has also been accomplished. In the case of appropriate geminal disubstitution of the terminal double bond as in 18, 5endo-dig cyclisation is favored by the formation of a tertiary carbocation. (Scheme 12, Eq. 1). ${ }^{[26]}$

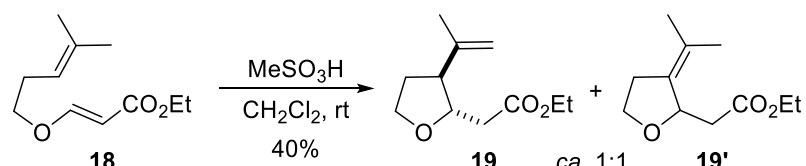<smiles>CCOC(=O)C=COC(CC#Cc1ccccc1)CCC(=O)O</smiles><smiles>CCOC(=O)CC1OC(CC)C[C@H]1C(=O)c1ccccc1</smiles>

Scheme 12. Formation of 5-membered rings through Prins-type cyclisations.

The tetrahydrofurans 19 and $\mathbf{1 9}^{6}$ are formed in equal amounts. The stereoselective synthesis of cis-2,5tetrahydrofuran by a Prins-cyclisation approach was achieved by replacing the appended olefin by an alkyne (Scheme 12, Eq. 2). ${ }^{[31}$ A substoichiometric amount of $\operatorname{In}(\mathrm{OTf})_{3}$ was used to promote the unusual 5-endo-trig cyclisation of $\mathbf{2 0}$, which proceeded under formation of the ketone $\mathbf{2 1}$ from hydrolysis of the carbocation after cyclisation.

An elegant Mukaiyama aldol-Prins cyclisation cascade reaction was introduced by Rychnowsky.[32] Lewis acid-activation of an aldehyde delivers the electrophilic promoter for the formation of the intermediate oxonium ion via an aldol reaction (Scheme 13).
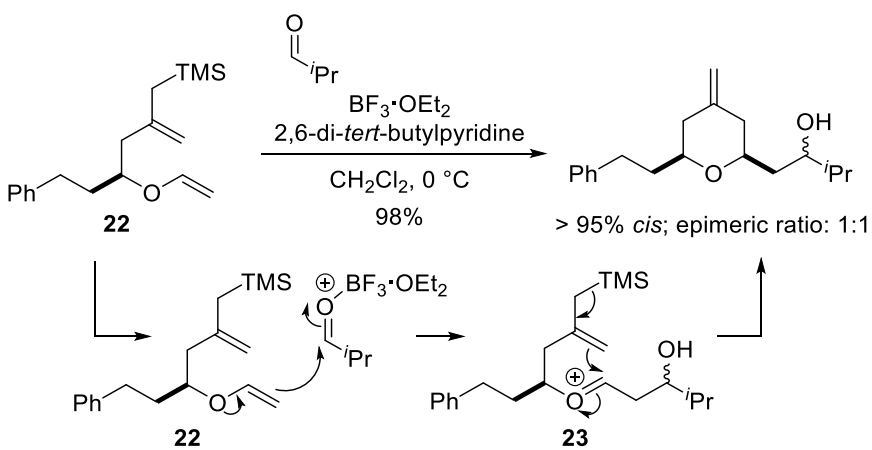

Scheme 13. Aldol-Prins cyclisation cascade.

Highly reactive allyl silanes were used instead of simple alkenes in the Prins cyclisation to enhance the nucleophilicities of the latter and to prevent concomitant enol ether oligomerisation under the Lewis acidic conditions. The first step is a Lewis acid-promoted nucleophilic addition of the enol ether moiety of $\mathbf{2 2}$ to the aldehyde. The thus formed oxocarbenium intermediate $\mathbf{2 3}$ then undergoes the typical Prins cyclisation. This approach delivers 2,6disubstituted 4-exo-methylenic tetrahydropyrans regio- and stereoselectively and was applied to the total synthesis of the leucascandrolide A macrolide. ${ }^{[32]}$ All the reactants were, however, applied in excess. The heterocyclisation of an enol ether triggered by an initial aldol reaction has been reported by Mackenzie et al., who used $10-20$ mol\% of TMSOTf as the catalyst. ${ }^{[33]}$

The method was extended to simple alkene substrates such as $\mathbf{2 4}$, easier to prepare than the corresponding allyl silanes. A stoichiometric amount of $\mathrm{TiBr}_{4}$ was used as the Lewis acid, affording the 4bromo tetrahydropyran $\mathbf{2 5}$ with a strong preference (>95:5) for the all-cis compound (Scheme 14). ${ }^{[34]}$ 


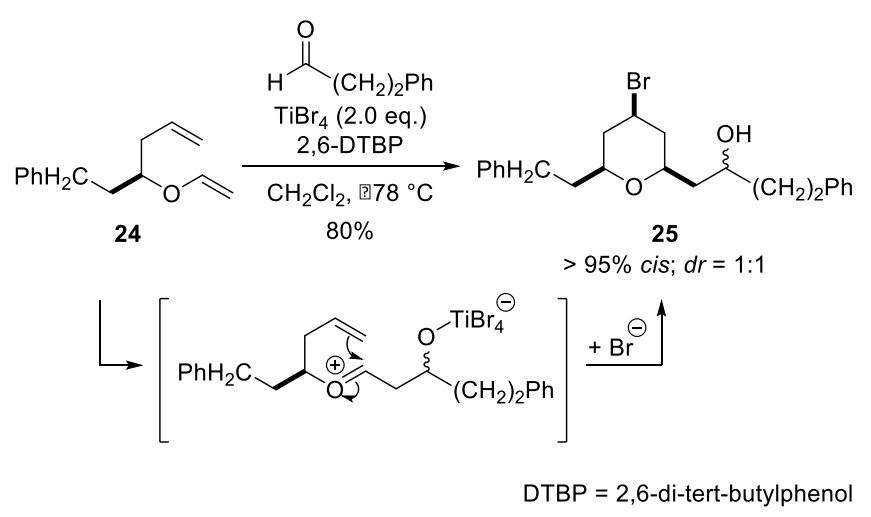

Scheme 14. Tandem Mukaiyama-Michael cyclisation of simple olefins.

The expected Prins cyclisation product 29 was not observed, however, when the aldehyde was replaced by methyl vinyl ketone (Scheme 15). A MukaiyamaMichael cascade reaction occurred instead. ${ }^{[35]}$ In fact, the oxocarbenium intermediate $\mathbf{2 6}$ resulting from conjugate addition of the enol ether to the enone underwent rapid equilibration towards $\mathbf{2 7}$ via sigmatropic 2-oxonia-Cope rearrangement.

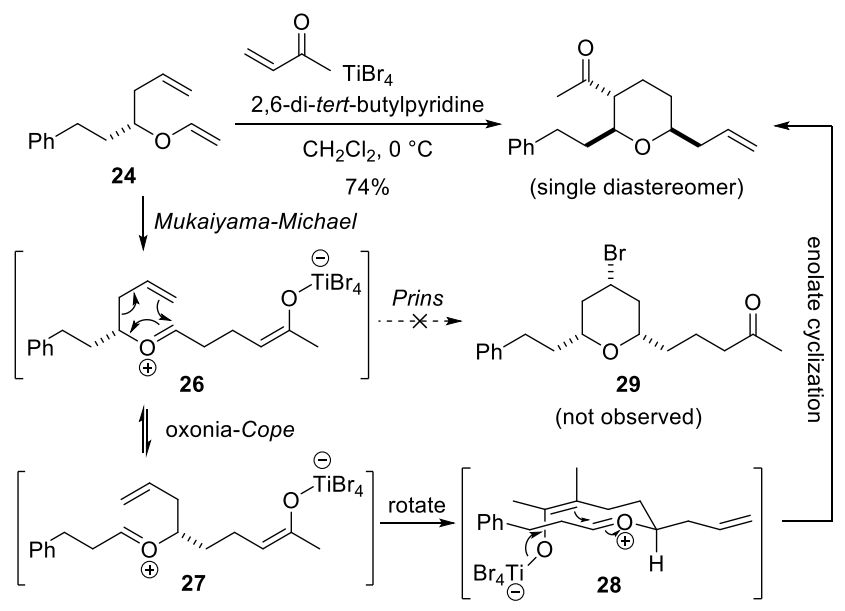

Scheme 15. Tandem Mukaiyama-Michael cyclisation cascade.

The stereogenic center in the starting material was shown to be inverted in the product as a consequence of the necessity of oxonium ion $\mathbf{2 7}$ to adopt the chairlike transition state $\mathbf{2 8}$ required for the ensuing enolate cyclisation. The final product was isolated as a single diastereomer due to a preferred all-equatorial alignment of the three substituents in the transition state. The synthetic utility of this tandem reaction was demonstrated by its application in total synthesis. ${ }^{[36]}$

Recently, Duñach et al. developed a Lewis superacid-catalysed cycloisomerisation of allene-enol ethers (Scheme 16). ${ }^{[37]}$ The enol ether was found to be activated preferentially by a catalytic amount of $\mathrm{Bi}(\mathrm{OTf})_{3}$ in the presence of a tethered allene. Electro- philic activation of the enol ether was followed by nucleophilic 5-exo-dig addition of the allene to the intermediate oxocarbenium species.

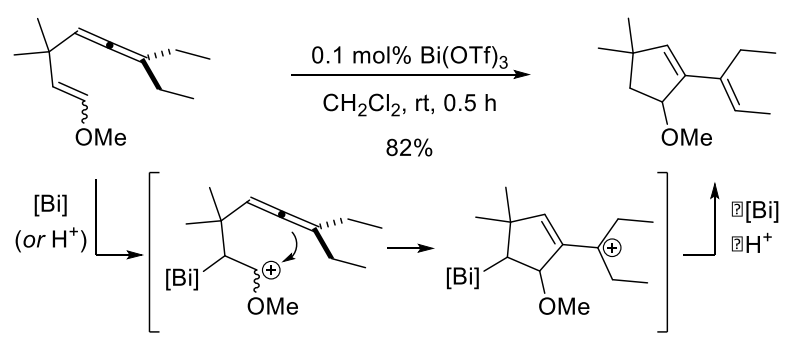

Scheme 16. $\mathrm{Bi}(\mathrm{OTf})_{3}$-catalysed cycloisomerisation of allene-enol ethers.

A series of enol and thioenol ethers readily cyclised in the presence of only $0.1 \mathrm{~mol} \%$ of the catalyst to afford cyclopentene derivatives under very mild conditions. The cyclisations were completely regioselective regarding the fact that both the allene and the enol ether can potentially undergo reactions with nucleophiles as well as electrophiles and are both susceptible to activation by a metal catalyst. The reactions were furthermore highly diastereoselective with respect to the configuration of the newly formed side-chain double bond. A quite general applicability of this novel cycloisomerisation was demonstrated and either functionalised cyclopentenes (Scheme 16) or dihydrofuran derivatives (Scheme 17, Eq. 1) could be accessed using differently substituted enol ethers.

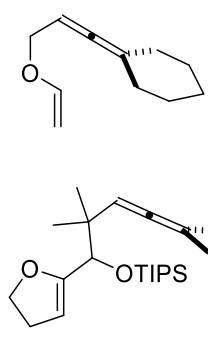
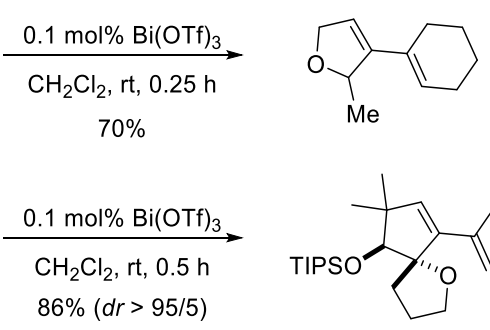

Scheme 17. Extension to other allene enol ether substrates.

Cyclic enol ethers led to interesting spirobicyclic tetrahydrofuran and tetrahydropyran derivatives of increased molecular complexity (Scheme 17, Eq. 2). It is worth mentioning that in the case of cyclic enol ether substrates a free alcohol function did not interfere with the cyclisation, e. $g$. by nucleophilic addition to the allene, confirming that the latter is indeed not preferentially activated in the presence of $\mathrm{Bi}(\mathrm{OTf})_{3}$ as the catalyst. Accordingly, no elimination at the sensitive allylic position was observed under the Lewis acidic conditions. However, a better diastereoselectivity was achieved in the reactions of cyclic enol ethers, when the alcohol was masked as a bulky silyl ether (Eq. 2). The spiroethers were formed 
with the trans-configuration of the two oxygen atoms preferentially.

In a continuation of this work, the reactivity of 2hydroxy enol ethers $\mathbf{3 0}$ was also studied, where the allene was replaced by an olefinic moiety (Scheme 18). ${ }^{[38]}$

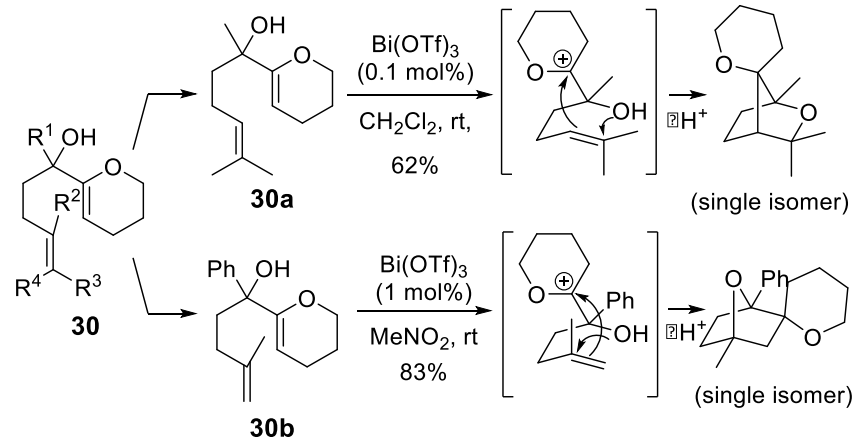

Scheme 18. Cycloisomerisation of $\alpha$-hydroxy enol ethers bearing a tethered olefin.

The $\alpha$-hydroxy enol ethers underwent a tandem double cyclisation in the presence of $\mathrm{Bi}(\mathrm{OTf})_{3}$ as the catalyst, leading to bridged bi- and tricyclic structures with excellent diastereoselectivity in all cases where dihydropyran was used as the enol ether. The observed reactivity can be explained by a preferential activation of the enol ether compared to the other susceptible chemical functions. The resulting oxocarbenium intermediates then undergo an intramolecular nucleophilic attack of the tethered olefin under formation of the first ring. The regioselectivity of this step is hereby governed by the stability of the ensuing carbocation. While precursors 30a bearing an internal olefin underwent a 5-exo-trig cyclisation via an intermediate prenyl carbocation, 2oxa enol ethers 30b with a tethered terminal alkene followed a 6-endo pathway to afford 7-oxabicyclo[2.2.1] heptanes with complete antidiastereoselectivity in nitromethane as the solvent. It is worth noting that even in the presence of the activated benzylic alcohol, enol ether activation remained the preferred process and no elimination at the benzylic position occurred. The same situation held true for five- and six-membered cyclic, as well as acyclic enol ethers. The high level of diastereoselectivity observed in these cycloisomerisations may be an indication for a pseudo-concerted mechanism, where the stereochemistry at the new ring-junction is determined by the conformation of the starting olefin according to the StorkEschenmoser paradigm. ${ }^{[39]}$ Indeed, mechanistic studies suggested a concerted polycyclisation of the carbocationic intermediate after electrophilic enol ether activation, involving a 5-exo-trig cyclisation of the enol ether and the olefin unit with a concomitant unusual syn-addition of the hydroxyl group. Biomimetic stereospecific cationic cyclisations of polyunsaturated alcohols for the synthesis of fused oxygen-containing heterocycles have been reported to proceed mainly through an anti-addition of the hydroxyl group across the original double bond. ${ }^{[40]}$

\section{c) Cyclisations of enol ethers with aromatic units}

The In the field of polycyclic aromatic hydrocarbon synthesis, enol ethers have gained attention as reactive promoters for the intramolecular carboncarbon bond formation of ortho-functionalised biaryls towards phenanthrene derivatives and a range of other polycyclic aromatic hydrocarbons. The $\mathrm{Bi}(\mathrm{OTf})_{3}$-catalysed cycloaromatisation of 2-(2arylphenyl)vinyl ethers has been reported (Scheme 19). .411

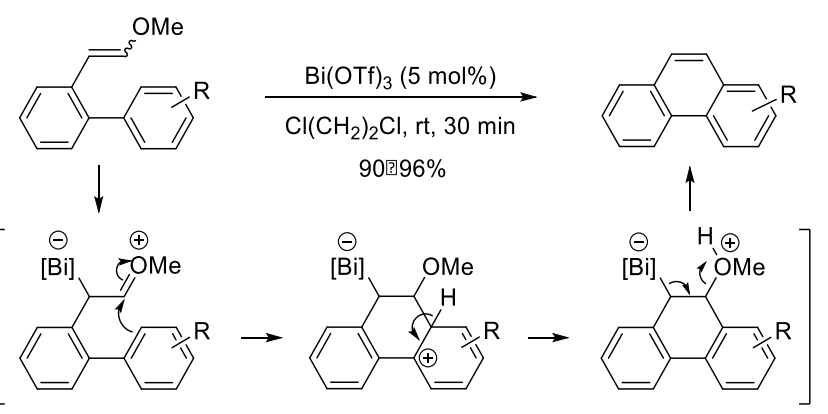

Scheme 19. Synthesis of phenanthrene derivatives through $\mathrm{Bi}(\mathrm{OTf})_{3}$-catalysed benzannulation.

The 2-(2-methoxyethenyl) biphenyls are thereby activated by the Lewis acid and subsequent nucleophilic attack of the second aryl moiety establishes the central ring of the phenanthrene system. Rearomatisation and protodemetalation release the catalyst under elimination of the alkoxy group and afford the final product. This cyclisation represents a remarkably mild, catalytic method, which broadens the scope of accessible phenanthrenes due to a broader functional group tolerance as compared to the relatively harsh conditions of classical benzannulations. If two orthoalkoxyvinyl groups are installed in the starting materials, double benzannulation can occur yielding more complex polyarenes. ${ }^{[42]}$

\subsection{Reactivity as the nucleophilic partner}

An alkoxy group enhances the nucleophilicity of an olefin and thus the ability of enol ethers to react with internal electrophiles is evident. Such a behavior tends to be apparent in the presence of unsaturated compounds activated by transition metal-based catalysts $(\mathrm{Au}, \mathrm{Pd}, \mathrm{Pt}, \mathrm{Ru})$. In an extension of their work on transition metal-catalysed enyne cyclisations, ${ }^{[43]}$ Echavarren and coworkers studied the 
behavior of enol ethers towards alkynes in intramolecular reactions (Scheme 20).

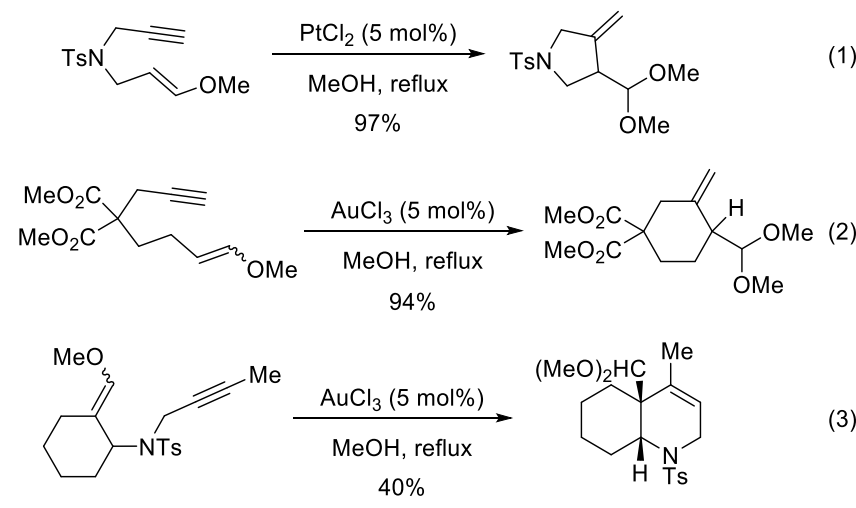

Scheme 20. Enyne cyclisations using enol ethers as electron-rich alkenes.

Reactions of enol ethers with alkynes were promoted by various late transition metal catalysts, such as $\mathrm{PtCl}_{2}, \mathrm{PdCl}_{2},\left[\mathrm{Cu}(\mathrm{MeCN})_{4}\right] \mathrm{PF}_{6}$ or $\mathrm{AuCl}_{3}$ to afford cyclic compounds in exo-dig or endo-dig cyclisations through an anti-addition of the enol ether and the metal to the alkyne. Demetalation occurred with concomitant addition of methanol leading to dimethyl acetals as the products. While the cyclisation of 1,6enynes (Eq. 1) was promoted with similar efficiency by $\mathrm{Pt}^{\mathrm{II}}, \mathrm{Pd}^{\mathrm{II}}$ and $\mathrm{Au}^{\mathrm{II}}$ chlorides and furnished the 5exo products exclusively, the formation of the sixmembered ring product (Eq. 2) through 1,7-enyne cyclisation required the use of the more reactive $\mathrm{Au}^{\text {III }}$ catalyst. Interestingly, an endo-dig cyclisation occurred with methoxy vinylidene cyclohexane precursors (Eq. 3), a reaction that usually involves metal vinylidene intermediates. The involvement of a gold vinylidene complex in this cyclisation was however excluded by the presence of the methyl substituent on the alkyne. A mechanism was proposed, where initial anti-addition of the enol ether and the metal to the alkyne leads to the formation of a cyclopropyl metal-carbene intermediate and the subsequent nucleophilic attack of $\mathrm{MeOH}$ can generally occur at either of the cyclopropyl carbons a or b (Scheme 21).

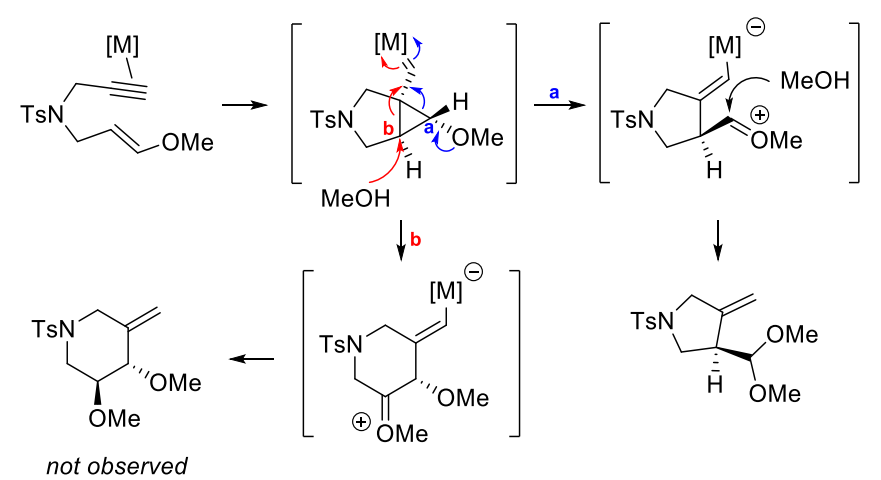

Scheme 21. Influence of the alkoxy group on the regioselectivity of cyclopropane ring-opening.

The strategic placement of the electron-donating alkoxy group was found to have a directing effect on the ring-opening of the cyclopropyl metal-carbene intermediate, leading to the selective formation of five- and six-membered carbocycles by 5-exo-dig or 6-exo-dig pathways, respectively, depending on the chain length of the cyclisation precursor. It is noteworthy that in all cases cyclisation occurs faster than methanolysis of the enol ether, which underlines the pronounced preference of the transition metals to coordinate to the alkyne rather than the electron-rich enol ether. Later, it was found that the same transformation could also be catalysed by a protic acid. ${ }^{[45]}$ 6-Endo-dig cyclisations have also been observed for certain substrates, but were more limited in scope than the correspondding exo-dig cyclisations.

Enyne cyclisations involving enol ethers have also been used in the preparation of partially saturated acenes. ${ }^{[46]}$ Gold(I)-catalysed cycloaromatisation of 1,7-enynes, in which the alkene is part of an enol ether function, afforded hydroacenes upon elimination of methanol (Scheme 22).

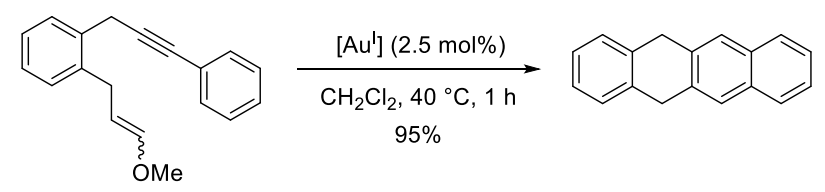

Scheme 22. Gold(I)-catalysed cycloaromatisation of enynes.

As opposed to the $\mathrm{Bi}(\mathrm{OTf})_{3}$-catalysed cycloaromatisation described above (Scheme 19), the carbophilic gold catalyst shows a preference to coordinate to the alkyne, ensuing nucleophilic attack of the enol ether.

The only cycloisomerisation mentioned in specialised literature surveys on that topic until 2015 involving an alkyl enol ether was reported by Echavarren and coworkers ${ }^{[47]}$ as an extension of their work on the $\mathrm{PtCl}_{2-}$ and $\mathrm{PdCl}_{2}$-catalysed enyne cycloisomerisation. $\stackrel{[43 \mathrm{a}, 44,47,48]}{ }$ In this specific case, 3oxabicyclo[4.1.0]hept-4-ene derivatives were formed in a completely regio- and stereoselective manner via an unusual intramolecular $\mathrm{Pt}^{\mathrm{II}}$-catalysed cyclopropanation of the enol ether by the tethered internal alkyne (Scheme 23). The authors propose that the cyclisation proceeds via the incipient formation of $\eta^{2}$-alkyne- $\mathrm{PtCl}_{2}$ complex 31. During the cyclisation step, the two new carbon-carbon bonds are formed from the face of the alkene opposite to the phenyl substituent, determining the diastereoselectivity. The platinum carbene $\mathbf{3 2}$ is then assumed to give the final dihydropyran by $\beta$-hydride elimination 

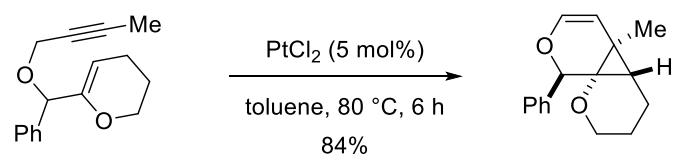

(single isomer)
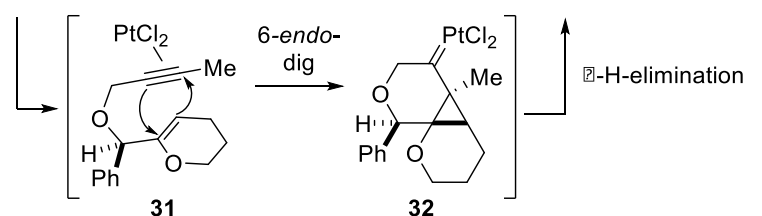

32

Scheme 23. Platinum-catalysed enyne-cycloisomerisation of enol ethers.

The strategic position of the alkoxy substituent conjugated to a strained three-membered ring was further utilised to facilitate the entry to sevenmembered rings by directing the selective cleavage of the cyclopropane ring.

Allyl enol ethers are typical substrates for Claisenrearrangements (Scheme 24). However, it has been shown that while a range of allyl ethers gave the expected Claisen-rearrangement products under thermal conditions, oxidative cycloalkenylation of the enol ether occurred in the presence of one equivalent of palladium(II) acetate. ${ }^{[49]}$

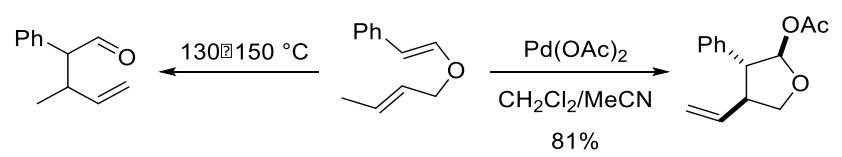

Scheme 24. Thermal Claisen rearrangement vs. $\mathrm{Pd}^{\mathrm{II}}-$ catalysed oxidative cyclisation of allyl enol ethers.

The authors propose that as opposed to the Prins-type cyclisations discussed above, it is not the enol ether, which establishes an interaction with the metal salt, but nucleophilic attack of the enol ether on the Pdcomplexed alkene is thought to be the ratedetermining step of the cyclisation. The resulting oxocarbenium ion is intercepted by an acetate anion to afford the 2-acetoxy tetrahydrofuran.

\section{Pericyclic reactions}

Pericyclic reactions are one of the most important classes of chemical transformations because of their inherent potential to provide a high degree of molecular complexity using a minimal number of steps. ${ }^{[50]}$ Several new bonds can be formed regio- and stereoselectively in a single step by simple orbital reorganisation. The reactions generally proceed in a concerted manner through a highly ordered transition state with a cyclic array of $\pi$-electrons, which allows for a predictable diastereoselection. ${ }^{[51]}$ Among pericyclic reactions, cycloadditions, electrocyclisations and sigmatropic rearrangements are the most extensively studied and used in organic synthesis. ${ }^{[52]}$ Enol ethers are commonly employed in inverse electron-demand Diels-Alder and other cycloaddition reactions and have proven particularly useful for the construction of five-and six-membered ring scaffolds in natural product syntheses. ${ }^{[53]}$ Some intramolecular variants have been developed and a selection of these, employing enol ethers, will be discussed in the following section without aiming at a comprehensive coverage of the available literature reports. Even though allyl vinyl ethers are classical substrates for [3,3]-sigmatropic Claisen rearrangements, ${ }^{[54]}$ and some tandem rearrangementcyclisation procedures have been reported, ${ }^{[55]}$ these reactions will not be discussed here, as they generally do not directly lead to the formation of a ring.

\subsection{Cycloadditions}

An intramolecular hetero-Diels-Alder reaction involving an enol ether has been employed in the total synthesis of desoxyloganin (Scheme 25). ${ }^{[56]}$ The enantiopure cyclisation precursor was prepared in seven steps starting from $(S)$-citronellal.

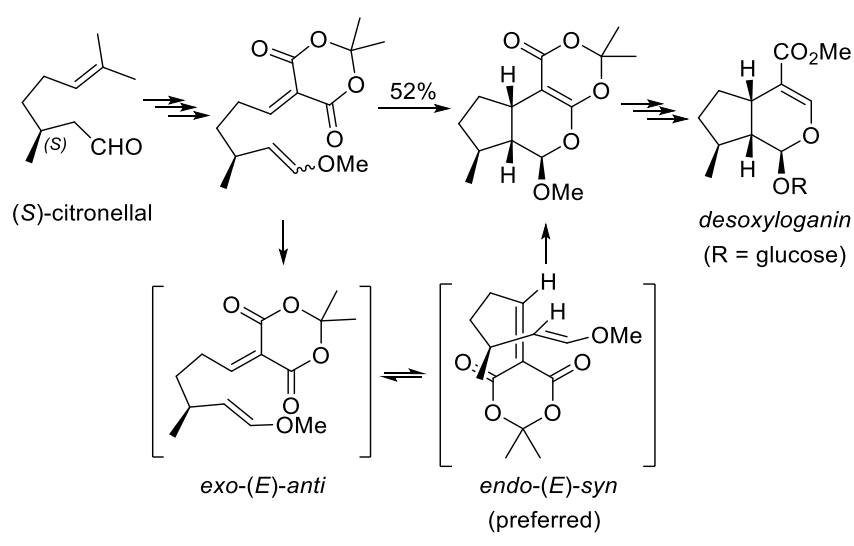

Scheme 25. Intramolecular Diels-Alder approach towards the total synthesis of desoxyloganin.

The reaction conditions for the cycloaddition step are not further specified and spontaneous cyclisation can be assumed. Of the two most probable transition states for the cycloaddition only an endo- $(E)-s y n$ alignment affords the product with the observed stereochemistry.

Nicolaou et al. adopted an intramolecular DielsAlder cycloaddition approach in their studies towards the total synthesis of hamigerans and their analogues, a familiy of marine metabolites with promising antiviral activity and cytotoxicity against certain cancer cell lines. ${ }^{[57]}$ Ortho-alkyl-substituted benzaldehydes bearing the alkoxy-dienophile in the tether served as the cyclisation precursors (Scheme 26). The challenging hamigeran skeleton comprising a [4.3.0] carbocyclic scaffold containing up to six stereogenic centers fused to an aromatic ring, was established by 
[4+2] cycloaddition between a photochemically generated hydroxy-ortho-quinodimethane species and the tethered dienophile. A powerful feature of this transformation is the stereospecificity of the mechanism, yielding the trans-stereochemistry at the newly generated ring fusion, as well as the stereoselective construction of two adjacent quaternary centers within the tricyclic framework.

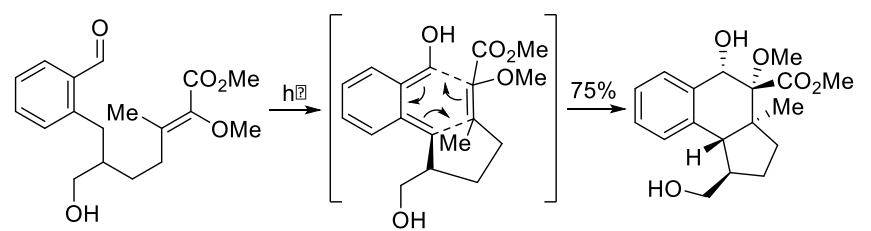

Scheme 26. Hamigeran-synthesis via intramolecular [4+2] cycloaddition employing an alkoxy-dienophile.

An intramolecular Diels-Alder cycloaddition involving a naphthofuran as the dienophile has been applied by Trauner et al. as the key step in their total synthesis of the complex naphthohydroquinone dimer rubioncolin B (Scheme 27).

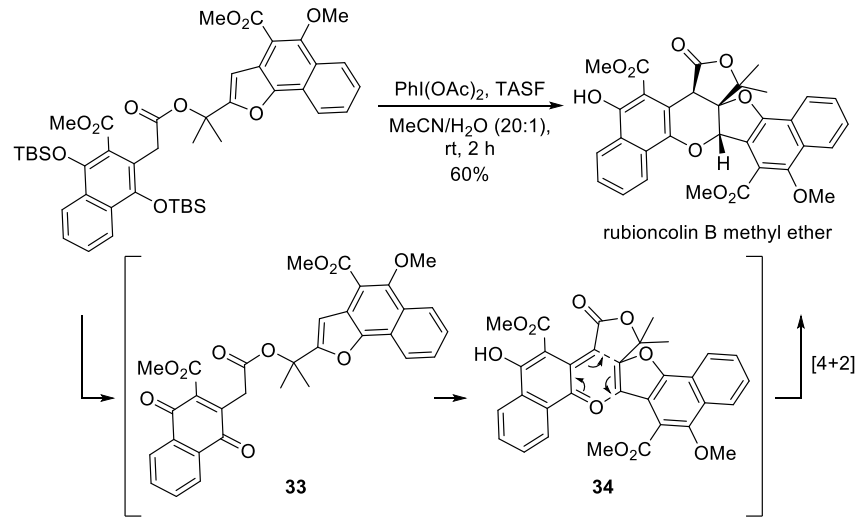

TASF = tris(dimethylamino)sulfonium difluorotrimethylsilicate

Scheme 27. Intramolecular cycloaddition towards rubioncolin B.

Upon deprotection of the silyl ethers within the cyclisation precursor, the resulting para-naphthoquinone 33 tautomerised into the corresponding ortho-quinone methide 34 . The latter served as the reactive diene and underwent spontaneous [4+2] cycloaddition with the enol ether to afford rubioncolin $B$ methyl ether in $60 \%$ yield. Demethylation then provided the free alcohol of the natural product.

The intramolecular [4+2]-cycloaddition of nitrosoalkenes and enol ethers has been developed. ${ }^{[59]}$ The nitrosoalkene is generated in situ by 1,4elimination of an $\alpha$-chloro silyl oxime and undergoes a stereospecific cycloaddition with the appended enol ether (Scheme 28). In the presence of KF, the reaction is very slow but under these conditions the nitroso-alkene is released at very low concentration, which reduces the amount of competing intermolecular reactions.

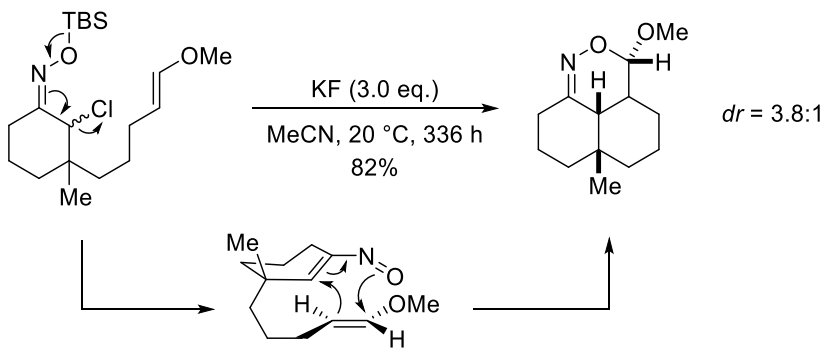

Scheme 28. Intramolecular cycloaddition of a nitrosoalkene to a tethered enol ether..

While the geometry of the starting silyl oxime as well as the orientation of the chlorine atom had no influence on the stereochemical course of the reaction, the configuration of the enol ether was important and two products were formed in a diastereomeric ratio of 3.8:1 with respect to the configuration at the oxygenated stereocenter. The cycloaddition is thought to proceed via a preferred transition state with an endo-orientation of the methoxy group relative to the nitrosoalkene in analogy to the inverse electron-demand secondary orbital interactions often observed in Diels-Alder reactions.

Similarly, a tandem double intramolecular $[4+2] /[3+2]$ cycloaddition of nitroalkenes has been reported. ${ }^{[60]}$ In the presence of $\mathrm{SnCl}_{4}$ as the Lewis acid at low temperature, the nitroalkenes underwent an intramolecular [4+2] cycloaddition with the enol ether as the more reactive dienophile (Scheme 29).

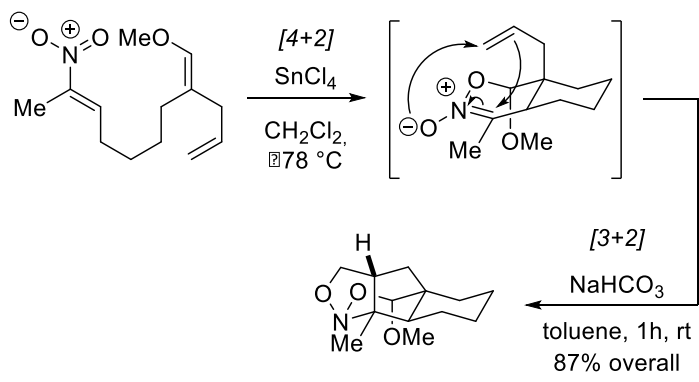

Scheme 29. Double intramolecular cycloaddition in the synthesis of a daphnilactone B precursor.

The resulting nitronate cycloadducts then underwent a second thermal $[3+2]$ cycloaddition with the alkene tether to afford tetracyclic nitroso acetals. In combination with hydrogenolysis of the nitroso acetals, the method proved useful for alkaloid synthesis and it was applied to the construction of the piperidine ring of daphnilactone $B .^{[61]}$ 
During their investigations on the intramolecular 1,3-dipolar cycloadditions of sugar-derived ketonitrones, Alonso et al. described a single example involving an enol ether (Scheme 30). ${ }^{.62]}$ In this procedure, ketosugars were transformed into the corresponding nitrones, which subsequently underwent a completely regio- and stereoselective $[3+2]$ cycloaddition with the tethered enol ether.

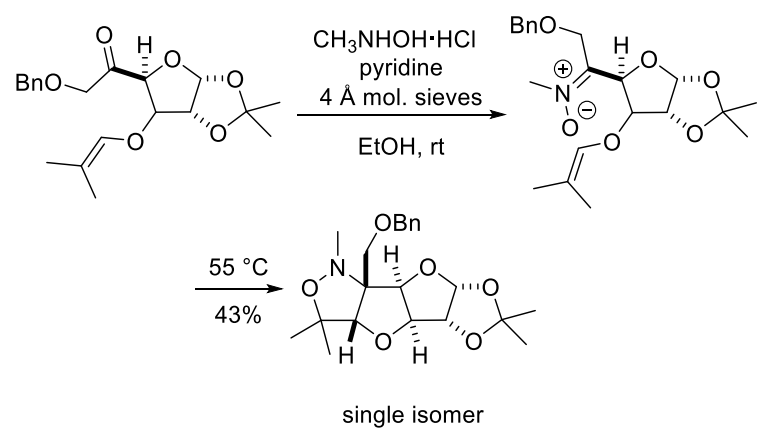

Scheme 30. 1,3-Dipolar ketonitrone-enol ether cycloaddition.

The ketofuranonitrone depicted in Scheme 30 afforded the highly oxygenated tetracyclic system as a single diastereomer. The synthetic potential of this transformation for the stereo-controlled preparation of targets bearing nitrogen-containing quaternary centers is unarguable.

\subsection{Electrocyclisations}

Electrocyclic reactions are an important subclass of pericyclic reactions and have received much attention in organic synthesis owing to their inherent ability to rapidly generate molecular complexity with a high degree of stereospecificity. ${ }^{[63]}$ As the above-described cycloadditions, they proceed in a concerted fashion with a cyclic array of $\pi$-electrons in the transition state. In electrocyclic ring closing reactions a new $\sigma$ bond is formed between the termini of an acyclic conjugated $\pi$-system, while a $\pi$-bond is broken. ${ }^{[64]}$ The stereochemical course of the reaction is defined by the conservation of orbital symmetry as proposed by Woodward and Hoffmann. ${ }^{[65]}$

The Nazarov reaction is a prominent example for a $4 \pi$-electron-5-atom electrocyclisation and the most extensively studied electrocyclic reaction. ${ }^{[66]}$ Cyclopentenones are formed by cyclisation of crossconjugated divinyl ketones in a process catalysed by strong Lewis acids. The thermal reaction involves a conrotatory $4 \pi$-electrocyclisation mechanism via an intermediary oxyallyl cation (Scheme 31 ).

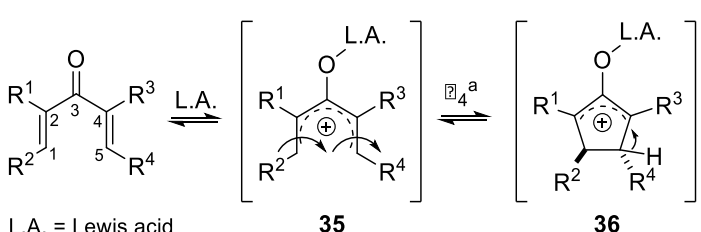

L.A. = Lewis acid

35

36

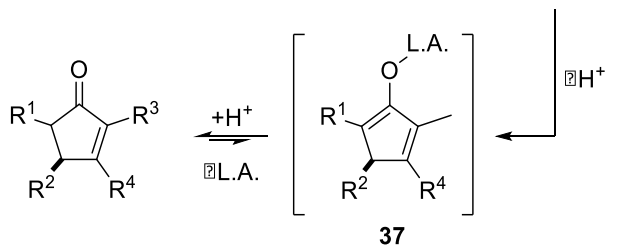

Scheme 31. Mechanism of the classical Nazarov reaction.

Complexation of the Lewis or Brønsted acid $\left(\mathrm{H}^{+}\right)$to the divinyl ketone leads to the formation of cyclopentadienyl cation $\mathbf{3 5}$ as the key intermediate, which upon $4 \pi$-electrocyclic ring closure provides oxallyl cation 36 with an anti-configuration of $\mathrm{R}_{2}$ relative to $R_{4}$. This stereospecificity is dictated by the conrotatory fashion of the ring closure enforced by an antarafacial overlap of the frontier orbitals located at the termini of the $\pi$-system. Proton elimination affords acid-bound enolate $\mathbf{C}$, which then evolves to the cyclopentenone as the final product via the ketoenol tautomeric equilibrium. The at first sight impressive synthetic elegance of the Nazarov process however suffers from several drawbacks. Proton elimination (36 $\rightarrow$ 37) is afflicted with regioselectivity issues and leads to the loss of a stereogenic center (C3). Reprotonation of the enolate $\mathrm{C}$ is not stereoselective (C5). Furthermore, strong acids in (over)stoichiometric amounts are usually required to efficiently promote the cyclisation, making the development of catalytic variants difficult. ${ }^{[66 f]}$

The first example of an enol ether involved in a Nazarov cyclisation was reported by Kocieńsky (Scheme 32), who observed the formation of an $\alpha$ hydroxycyclopentenone $\mathbf{3 9}$ as a side-reaction, when attempting the hydrolysis of the enol ether $\mathbf{3 8}$ under acidic aqueous conditions. ${ }^{[67]}$
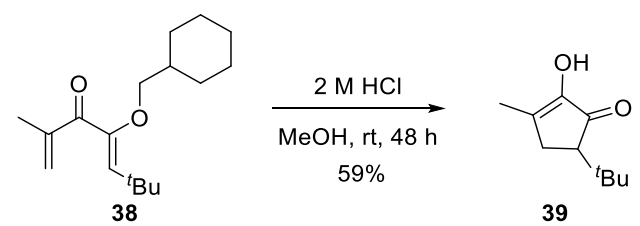

Scheme 32. Nazarov cyclisation under mild conditions enabled by the presence of an enol ether.

Shortly after this report, the Lewis acid-promoted Nazarov cyclisation of $\mathrm{N}$-acylhemiaminals towards the synthetically challenging tricyclic core skeleton of a cephalotaxine precursor was described (Scheme 33). 


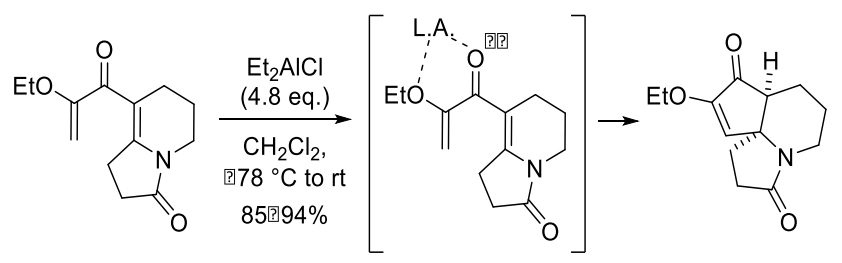

Scheme 33. Enol ether-assisted Nazarov cyclisation of $N$ acetyl hemiaminals.

This example demonstrated the beneficial effect of the $\alpha$-alkoxy substituent, since the same dienone lacking the enol ether moiety did not undergo the cyclisation under the described conditions. The authors proposed a bidentate chelating complexation of the Lewis acid to both the carbonyl oxygen and the adjacent alkoxy substituent, enforcing the favorable s-trans conformation of the enone required for cyclisation. A similar effect had been observed for the base-promoted cyclisation of $\alpha, \beta$-unsaturated $\alpha$ diketones. In the presence of magnesium methoxide, the respective magnesium complex is formed from the enolate of the $\alpha$-dicarbonyl system, holding the precursor in the proper conformation for cyclisation. ${ }^{[69]}$.

Following this finding, Trauner and coworkers reported the Nazarov cyclisation of 2-alkoxy-1,4pentadien-3-ones, catalysed by $\mathrm{AlCl}_{3}$ (Scheme 34). ${ }^{[70]}$ The cyclopentenones were formed with excellent diastereoselectivity. Whereas acyclic enol ethers furnished the products in good yields, corresponding dihydrofuran derivatives failed to give a clean product
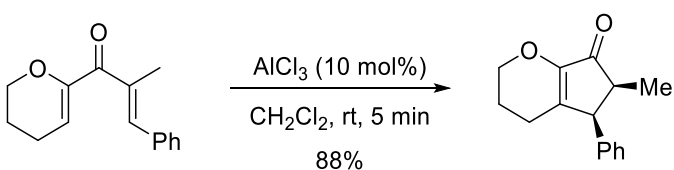

Scheme 34. Regio- and stereoselective catalytic Nazarov cyclisation facilitated by an $\alpha$-alkoxy group.

The seminal work of Frontier et al. led to a deeper understanding of the steric and stereoelectronic influence of substituents on the divinyl ketone and highlighted the strongly promotive effect of strategically placed alkoxy groups. In addition to a chelating effect induced by the $\alpha$-oxygen, the electron-donating substituent may also increase the electron density on the terminal carbon of the pentadienyl cation, thus lowering the activation barrier for cyclisation. Furthermore, it excerts a stabilizing effect on the cyclopentadienyl cation intermediate. And finally, the positive charge is effectively directed to one $\alpha$-carbon, enabling a highly regioselective elimination. ${ }^{[66 f]}$ In other words, the introduction of the alkoxy substituent polarises the divinyl ketone, dividing it into an electron-rich $\pi$ system (nucleophile) and an electron-poor $\pi$-system (electrophile), thus ensuring a regioselective course of the reaction. These auspicious properties of enol ether-containing substrates have paved the way for catalytic versions of the Nazarov process. A strongly polarised divinyl ketone bearing a donor and an acceptor group on both $\alpha$-carbons was cyclised quantitatively with complete regio- and stereocontrol in the presence of a catalytic amount of copper(II) triflate at ambient temperature (Scheme 35).
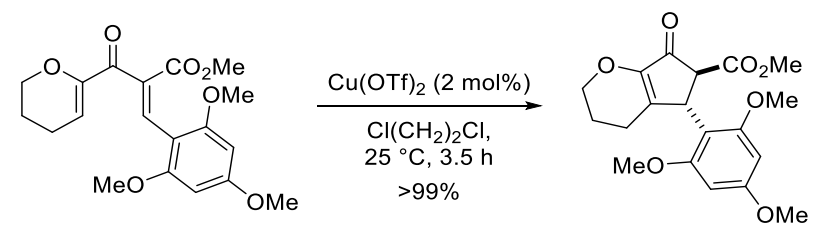

Scheme 35. The polarised Nazarov cyclisation.

In addition to the rate-enhancing effect of the $\alpha$ dihydropyranyl group, the electron-withdrawing substituent at the C4-position allowed for thermodynamic epimerisation to occur at this stereocenter, which accounts for the exclusive formation of the trans-isomer. In the course of these studies, the Frontier group also reported on a tandem electrocyclisation-Michael addition sequence of similar enol ether substrates, catalysed by a dicationic iridium(III) complex. ${ }^{[72]}$

An interesting unusual palladium-catalysed cyclisation has been observed by Tius and coworkers. $^{[73]}$ 2-Hydroxycyclopentenone $\mathbf{4 0}$ was obtained from $\alpha$-alkoxy-substituted dienone 41 using $1 \mathrm{~mol} \%$ of $\mathrm{PdCl}_{2}(\mathrm{MeCN})_{2}$ (Scheme 36).

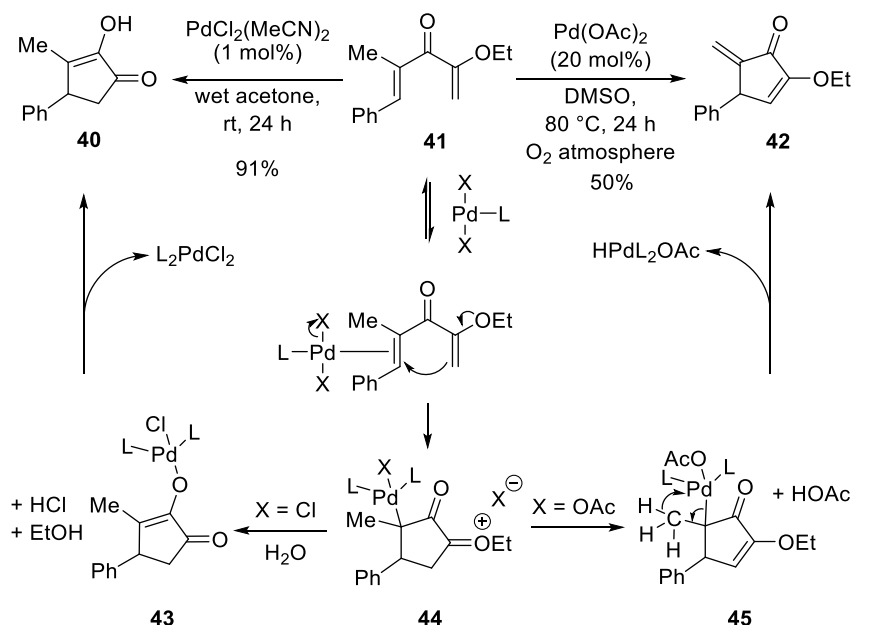

Scheme 36. Divergent palladium catalysis in the electrocyclisations of $\alpha$-alkoxy dienones.

In the presence of $\mathrm{Pd}(\mathrm{OAc})_{2}$, cross-conjugated cyclopentenone $\mathbf{4 2}$ was formed. An unusual mechanism has been proposed, where activation of the carbonyl group as for conventional acid-catalysed 
Nazarov cyclisations is not thought to be the first step. Instead, reversible $\pi$-coordination of the palladium salt to the electron-poor olefin initiates cyclisation and palladium enolate $\mathbf{4 4}$ is formed. In the case of $\mathrm{Pd}(\mathrm{OAc})_{2}$, proton elimination from 44 leads to $\mathbf{4 5}$, from which 42 is released through $\beta$-H elimination. When $\mathrm{PdCl}_{2}$ is used, the enol ether is hydrolysed with concomitant formation of $\mathrm{HCl}$. Decomposition of enolate species $\mathbf{4 3}$ regenerates the catalyst and releases 2-hydroxycyclopentenone $\mathbf{4 0}$. The difference between the two reaction pathways is thought to be due to basicity differences between the counter anions.

The synthesis of carbocycle-fused furans via a gold-catalysed tandem heterocyclisation/Nazarov cyclisation has been reported. ${ }^{[74]}$ Interestingly, whether hetero- or electrocyclisation occurs as the first step was found to be dependent on the solvent, which is thought to have an influence on the coordination mode of the catalyst to the substrate (Scheme 37). In acetonitrile as a strongly coordinating solvent, the effective ion radius of the gold cation is considerably increased and the more accessible carbonyl group is activated preferentially. Dichloromethane on the other hand coordinates only weakly to the catalyst, rendering the $\mathrm{Au}(\mathrm{III}) \mathrm{L}_{\mathrm{n}}\left(\mathrm{CH}_{2} \mathrm{Cl}_{2}\right)$ complex compact enough to attack at the kinetically favored cavity between the alkyne and the alkene. In both cases, the alkoxy group is necessary for the stabilisation of carbocationic intermediates.

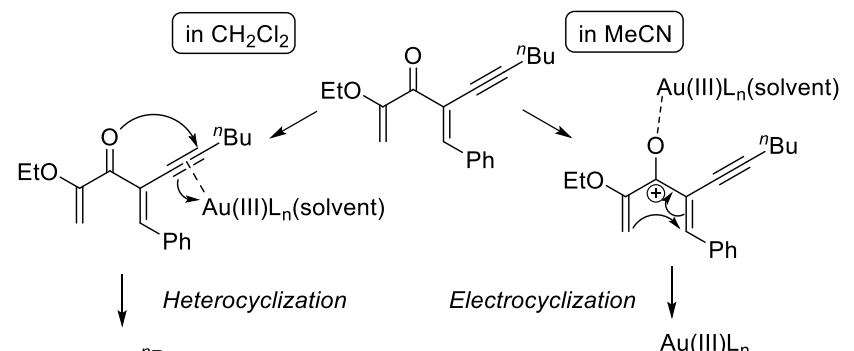

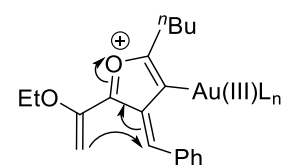<smiles>CCOC1=C(C#CC(C)(C)C)CCC1=O</smiles>

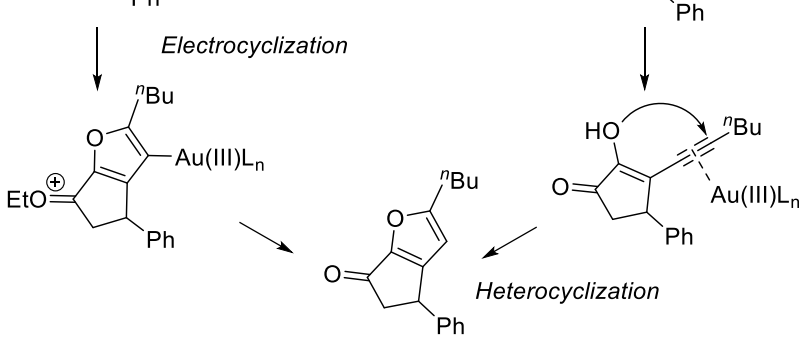

Scheme 37. Solvent-dependent mechanistic divergence in the gold-catalysed tandem heterocyclisation/Nazarov cyclisation of $\alpha$-ethoxy divinyl ketones.

Following these discoveries, several reports on Nazarov reactions involving activated $\alpha$-alkoxy- substituted divinyl ketone precursors emerged in the literature, using Lewis acids, ${ }^{[75]}$ mineral acids, ${ }^{[76]}$ organocatalysts, ${ }^{977]}$ or even no catalyst at all in a thermal, microwave-promoted reaction. ${ }^{[78]}$ Asymmetric variants have been disclosed by Trauner, ${ }^{[70,79]}$ Rueping ${ }^{[80]}$ and others. ${ }^{[81]}$

Various innovative methods for the unconventional generation of the incipient pentadienyl cations have been developed, some of them making use of the particular reactivity of enol ethers. ${ }^{[66 b]}$ The generation of the characteristic Nazarov-intermediate through activation of alkoxytrienes has been thoroughly investigated by Occhiato and Prandi. ${ }^{[82]}$ Cyclopentafused hexahydro[1]pyridin-7-ones were obtained under mild conditions using Amberlyst 15 resin as the proton source. The pentadienyl cation is formed via protonation of the distal double bond, enabled by the electron-donating character of the alkoxy group (Scheme 38). ${ }^{[82 \mathrm{~d}]}$ The presence of the nitrogen (or other heteroatom) was found to be essential to promote a successful cyclisation, due to its stabilising effect on the ensuing oxyallyl cation intermediate. Corresponding carbacyclic trienes did not afford any cyclised products but underwent hydrolysis of the enol ether under the acidic conditions, furnishing exclusively the conventional divinyl ketones, which did not undergo Nazarov cyclisation under the present mild conditions. The reaction outcome was shown to be dependent on the ring size of the heterocycle, the substituents on the alkoxytriene moiety and the nature of the heteroatom. ${ }^{[82 \mathrm{c}]}$ The authors proved steric factors to play a role in the torquoselectivity of the cyclisation. $\frac{[82 \mathrm{~b}, 82 \mathrm{c}]}{}$

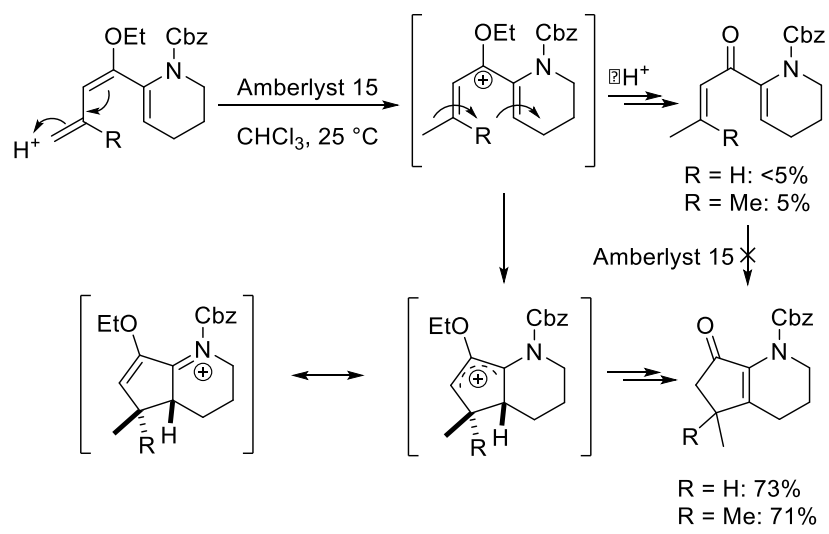

Scheme 38. Cyclisation of alkoxytrienes under mildly acidic conditions.

In the case of dihydropyran-derived substrates, the sense of conrotation was determined by the 2-methylsubstituent and the trans-product was predominantly formed (Scheme 39). 
<smiles>CCOC(CC)C1CCC[C@@H](C)O1</smiles>
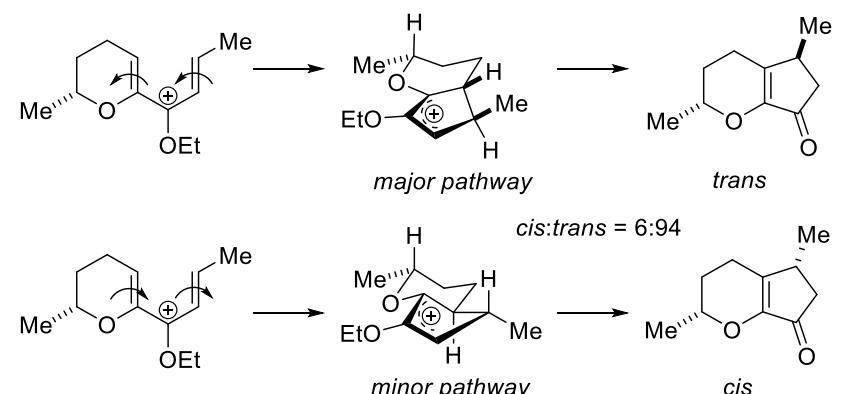

Scheme 39. Diastereoselection in alkoxytriene-cyclisations of dihydropyran-derived substrates.

It was proposed that a better orbital overlap is achieved when the dihydropyran ring adopts a boatlike conformation in the transition state with an antiorientation of the two methyl groups. This method allowed for a rapid and facile entry to a range of cyclopentannulated heterocyclic structures, including dihydronaphthalenes, isochromenes and indoles. ${ }^{[77 \mathrm{a}, 82 \mathrm{a}, 83]}$

Interestingly, a divergent reactivity was observed for the dihydropyran-containing substrates, due to competing effects caused by the substituents on the alkoxydienyl moiety (Scheme 40$).{ }^{[84]}$ When the distal double bond was less electron-rich $(\mathrm{R}=\mathrm{H})$, the usual fused ring system was formed following pathway $b$, whereas pathway a became predominant, when a gem-dimethylsubstituted terminal double bond was used. In the latter case, $4 \pi$-electro-cyclisation led to spirocyclic ketones with a high degree of stereoselectivity. For the unsubstituted precursor, vinylogous protonation of the acyclic enol ether results in oxallylcation $\mathbf{4 7}$ where the positive charge is sufficiently stabilised by the ethoxy group. Oxallyl cation 46 on the other hand, benefits from stabilizing effects of both the dihydropyranyl moiety and the two methyl substituents. In consequence, activation of the cyclic enol ether becomes more likely.

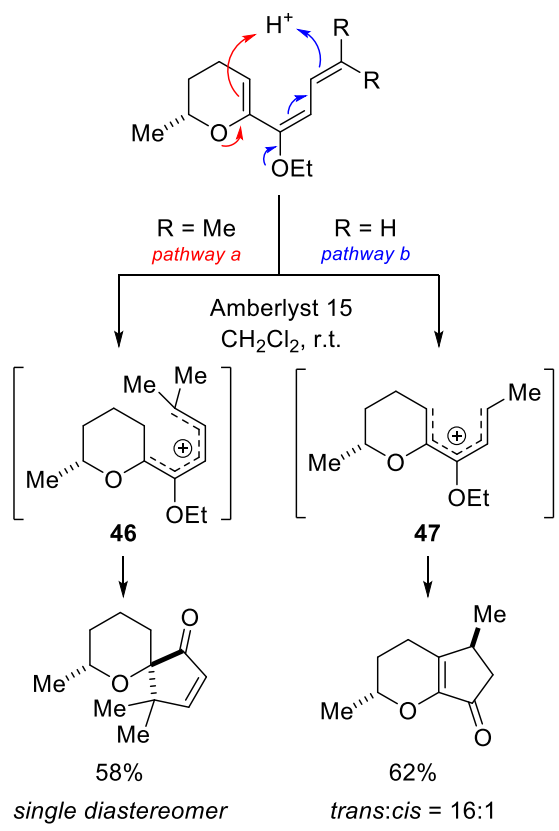

Scheme 40. Chemodivergence in the cyclisation of dialkoxytrienes.

A similar mode of activation was reported for the Nazarov-type cyclisation of dimethoxyhexatrienes in the presence of excess TFA, yielding a 1:1 mixture of regioisomeric cyclopentenones (Scheme 41). ${ }^{[85]}$ This transformation is a vivid example for the subtle stereoelectronic effects brought upon by the alkoxy groups. The positive charge in the incipient oxyallyl cation 48 is delocalised on the first methoxy group, whereas the second one has a stabilizing effect on the ensuing cyclopentadienyl cation 49. Unfortunately, the elimination step is not regioselective, because direct hydrolysis towards the methoxycyclopentenone is competing with proton elimination and subsequent hydrolysis of the less substituted enol ether.

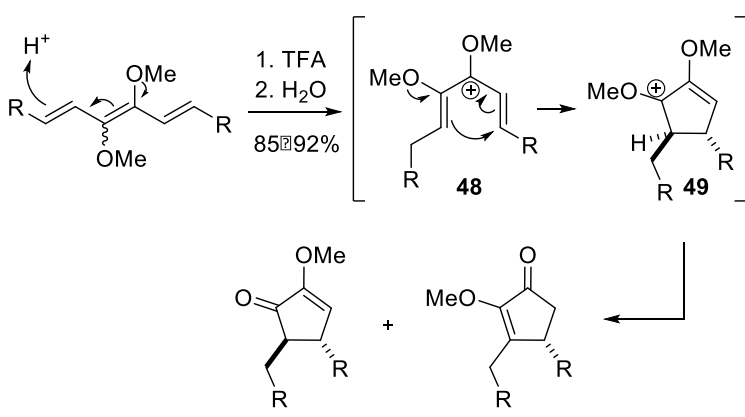

Scheme 41. Electrocyclisation of dimethoxyhexatrienes.

Alcohol ionisation is another means to generate the incipient oxyallyl cation. Except for the work of the Tius group regarding the Nazarov cyclisation of allene ethers, $\stackrel{[86]}{ }$ reports on the cyclisation of divinyl carbinols bearing an alkyl enol ether function are scarce. An example was reportet by Tius in 1999, who used (bis)allylic alcohols for the synthesis of $\alpha$ - 
perfluorinated cyclopentenones in the presence of a stoichiometric amount of $\mathrm{BF}_{3} \cdot \mathrm{Et}_{2} \mathrm{O}$ (Scheme 42). Enol ether-hydrolysis after the ring-forming step leads to the loss of the THP ether as a stable oxocation and to the formation of either cyclopentenones from tertiary, or hydroxycyclopentenones from secondary alcohols.

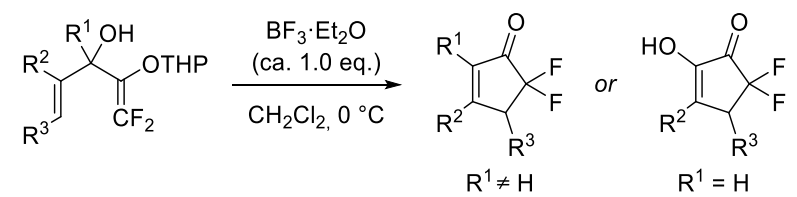

Scheme 42. Synthesis of difluorocyclopentenones by cyclisation of 2-oxa difluorovinyl ethers.

An electrocyclic ring rearrangement via alcohol ionisation involving dihydropyran-derived tertiary 2alkoxy diallylalcohols has been reported Lempenauer et al. (Scheme 43).

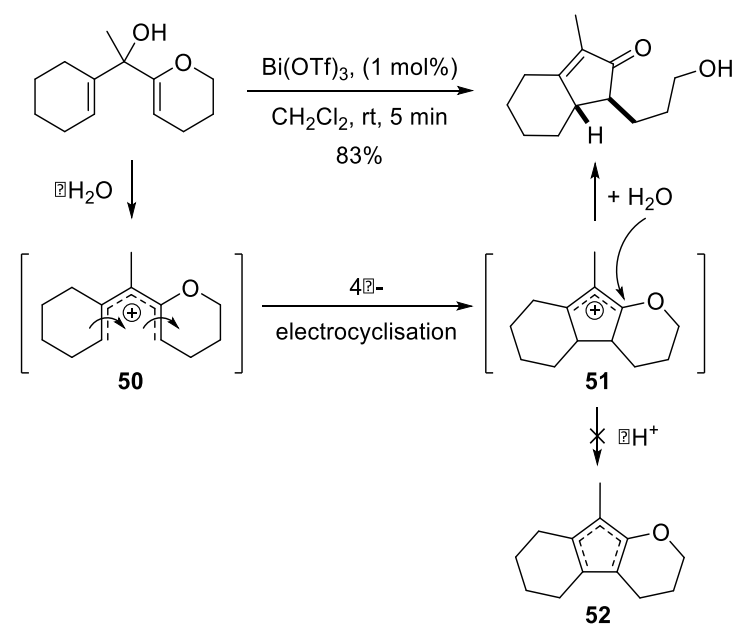

Scheme 43. $\operatorname{Bi}(\mathrm{OTf})_{3}$-catalysed electrocyclisation of diallyl alcohols.

The reaction catalysed by bismuth(III) triflate under very mild conditions and proceeds within five minutes at room temperature using only $1 \mathrm{~mol} \%$ of the catalyst. The cyclopentenone products are obtained with excellent yield and stereospecificity, furnishing the trans-diastereomer exclusively. It should be noted here, that proton elimination to form the corresponding cyclopentadienes $\mathbf{5 2}$ does not occur under the reaction conditions. Oxallyl cation $\mathbf{5 1}$ is instead intercepted by the previously expelled water molecule in a completely atom economic intramolecular reaction. The cyclopentenone is formed as the thermodynamically more stable openchain form of an intermediate lactol. The effect of enol ether hydrolysis in the classical Nazarov cyclisation of dihydropyran-containing divinyl ketones was investigated by Kobayashi, who used a surfactant-combined Lewis acid catalyst in aqueous medium. ${ }^{[89]}$ Epimerisation of the enone under the reaction conditions was further ruled out by experimental evidence, emphasizing the excellent diastereospecificity of the cyclisation.

The synthesis of six-membered carbocycles through a Nazarov-type electrocyclisation has been rendered possible by the so-called homo-Nazarov cyclisation, which uses alkenyl cyclopropyl ketones as the precursors to form substituted cyclohexenones. The first example of a catalytic enol ether-homoNazarov cyclisation has been reported using a vinyl ether cyclopropyl ketone (Scheme 44, Eq. 1). ${ }^{[90]}$ The dihydropyran-fused cyclohexenone product was formed in $70 \%$ yield after 15 minutes in the presence of $20 \mathrm{~mol} \%$ of 4 -toluenesulfonic acid. Once again, the enol ether moiety was essential to achieve efficient cyclisation. A range of Lewis acids was also tested but led to polymerisation of the sensitive cyclopropyl ketones. The authors proposed a stepwise mechanism with the cyclopropane-opening as the rate-limiting step.

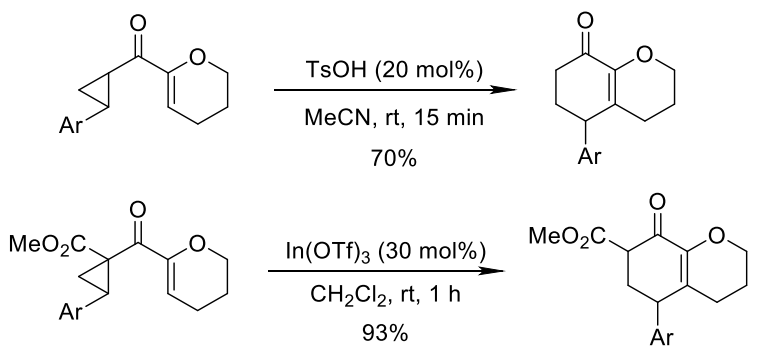

Scheme 44. Homo-Nazarov reactions of 2-oxo enol ethers. $\mathrm{Ar}=4$-methoxybenzene.

Shortly after this report, France and coworkers published a Lewis acid-catalysed homo-Nazarov cyclisation of similar substrates (Scheme 44, Eq. 2). ${ }^{[91]}$ In this case, an electron-withdrawing $\alpha$ carbomethoxy group on the cyclopropane unit facilitated ring opening and prevented polymerisation in the presence of indium(III) triflate as the catalyst.

Whereas $\alpha$-alkoxy substituents have a favorable effect on the cyclisation due to the stabilisation of the cyclopentadienyl cation, the inverse effect should be true for $\beta$-alkoxy substituents. Nevertheless, Shindo and coworkers achieved the cyclisation of reverse enol ether-substrates to afford $\alpha$-alkoxy cyclopentenones (Scheme 45, Eq. 1). ${ }^{[92]}$ The presence of the $\beta$ alkoxy group proved to be mandatory, precursors lacking the enol ether function did not furnish any cyclised product. Experimental results suggested that the formation of the quaternary center was an intermolecular process rather than an intramolecular alkoxide shift. When nucleophilic attack at the $\alpha$ carbon was prevented for steric reasons, proton elimination led to $\alpha$-exomethylene compounds (Scheme 45, Eq. 2). ${ }^{[93]}$ 
<smiles>C=C(C)C(=O)/C(OC)=C(\C)c1ccccc1</smiles>

$$
\begin{gathered}
\underset{\mathrm{Sc}(\mathrm{OTf})_{3}(10 \mathrm{~mol} \%)}{\mathrm{MeOH}(10 \text { eq. })} \\
\underset{\mathrm{CH}_{2} \mathrm{Cl}_{2}, \mathrm{rt}, 3 \mathrm{~min}}{89 \%}
\end{gathered}
$$<smiles>[R]C=C(C)C(=O)C(C)=C([R])OCC</smiles>

$\mathrm{R}^{1}=\mathrm{CH}_{2} \mathrm{OTBS}$ $\mathrm{R}^{2}=\left(\mathrm{CH}_{2}\right)_{4} \mathrm{OMe}$

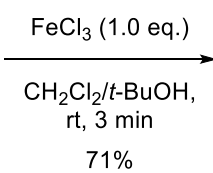

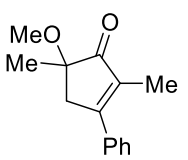<smiles>[R]C1=C([N+](=O)[O-])C([R])C(=C)C1=O</smiles>

Scheme 45. Scandium(III) and iron(III)-catalysed cyclisation of $\beta$-alkoxy divinyl ketones.

An asymmetric version of this reaction has been provided by the same group, as the first example of a catalytic enantioselective interrupted Nazarov cyclisation (Scheme 46). ${ }^{[94]}$
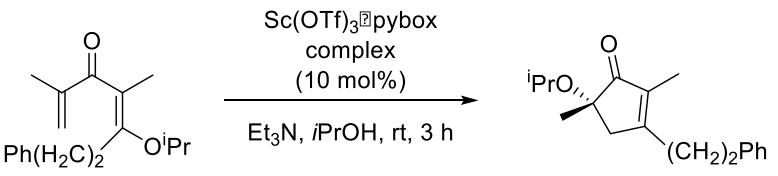

$55 \%$ yield, $91 \%$ ee

pybox $=$ pyridine $($ bis $)$ oxazoline

Scheme 46. Asymmetric electrocyclisation using a chiral scandium complex.

The asymmetric quarternary center at the $\alpha$-carbon was established with moderate to good enantiomeric excesses (up to 91\%) using a chiral scandium bis(oxazoline) complex in analogy to the results reported by Trauner. ${ }^{[70,79]}$

\section{Conclusions}

Among the plethora of functional groups amenable to Lewis or Brønsted acid chemistry, enol ethers have been described in only a few instances in the context of intramolecular reactions. One reason may be that the reactivity of enol ethers under acidic conditions is often delicate and difficult to control. As illustrated in the present review, the enol ether function mostly has a rate-enhancing effect or a directing influence on the regiochemistry of an elimination step after the cyclisation. Being both an electron-rich olefin and a masked carbonyl group, the enol ether function exhibits an inherently dual reactivity, making it susceptible to react with nucleophiles as well as with electrophiles. Sometimes, there may be a thin line between the nucleophilic and the electrophilic behavior, which may be influenced by other functional groups present within the molecule, by the catalyst or the reaction conditions.

\section{Acknowledgements}

PhD grant to L.L

\section{References}

[1] J. Cossy, A. Guérinot in Advances in Heterocyclic Chemistry, (Eds.: E. F. V. Scriven, C. A. Ramsden), Elsevier Inc., Amsterdam, Netherlands, 2016, pp. 107-142.

[2] a) B. Cacciuttolo, S. Poulain-Martini, F. FontaineVive, M. A. H. Abdo, H. El-Kashef, E. Duñach, Eur. J. Org. Chem. 2014, 7458-7468; b) I. Diaf, G. Lemière, E. Duñach, Angew. Chem. Int. Ed. 2014, 53, 4177-4180; c) E. Duñach, Chem. Biodiversity 2014, 11, 1752-1763; d) J. Godeau, S. Olivero, S. Antoniotti, E. Duñach, Org. Lett. 2011, 13, 3320-3323; e) F. Grau, A. Heumann, E. Duñach, Angew. Chem. Int. Ed. 2006, 45, 7285-7289.

[3] a) H. Yamamoto, D. L. Usanov, Organic Letters (Org Lett) 2012, 14, 414-417; b) C. Aubert, L. Fensterbank, P. Garcia, M. Malacria, A. Simonneau, Chem. Rev. 2011, 111, 1954-1993; c) A. Fürstner, Chem. Soc. Rev. 2009, 38, 3208-3221; d) V. Michelet, P. Y. Toullec, J.-P. Genêt, Angew. Chem. Int. Ed. 2008, 47, 4268-4315; e) E. Jiménez-Núñez, A. M. Echavarren, Chem. Rev. 2008, 108, 3326-3350; f) A. Fürstner, P. W. Davies, Angew. Chem. Int. Ed. 2007, 46, 3410-3449; g) G. C. Lloyd-Jones, Org. Biomol. Chem. 2003, 1, 215-236; h) C. Aubert, O. Buisine, M. Malacria, Chem. Rev. 2002, 102, 813-834; i) B. M. Trost, M. J. Krische, Synlett 1998, 1, 1-16; j) M. Lautens, W. Klute, W. Tam, Chem. Rev. 1996, 96, 49-92.

[4] F. Effenberger, Angew. Chem. Int. Ed. Engl. 1969, 8, 295-312.

[5] a) D. Tarabová, S. Soralová, M. Breza, M. Fronc, W. Holzer, V. Milata, Beilstein J. Org. Chem. 2014, 10, 752 760; b) V. D. Dyachenko, R. P. Tkachev, Russ. J. Org. Chem. 2003, 39, 757-793; c) V. P. Litvinov, Y. Y. Yakunin, V. D. Dyachenko, Chemistry Heterocycl. Compd. 2001, 37, 37-76; d) V. Milata, Aldrichim. Acta 2001, 34, $20-27$.

[6] a) P. Brownbridge, Synthesis 1983, 1-28; b) P. Brownbridge, Synthesis 1983, 85-104.

[7] a) A. Carrër, C. Péan, F. Perron-Sierra, O. Mirguet, V. Michelet, Adv. Synth. Catal. 2016, 358, 1540-1545; b) C. Schäfer, M. Miesch, L. Miesch, Chem. Eur. J. 2012, 18, 8028-8031; c) T. Godet, P. Belmont, Synlett 2008, 2513 2517; d) P. Langer, Synthesis 2002, 441-459.

[8] a) R. Feng, J. A. Smith, K. D. Moeller, Acc. Chem. Res. 2017, 50, 2346-2352; b) K. Moeller, Synlett 2009, 1208-1218; c) F. Tang, C. Chen, K. Moeller, Synthesis 2007, 3411-3420; d) S.H. K. Reddy, K. Chiba, Y. Sun, K. D. Moeller, Tetrahedron 2001, 57, 5183-5197.

[9] J. Mulzer (Ed.), Science of Synthesis: Houben-Weyl Methods of Molecular Transformations, Thieme Group, Stuttgart, 2008.

[10] a) J. Huet, O. Fabre, D. Zimmermann, Tetrahedron 1981, 37, 3739-3749; b) K. Hatada, K. Nagata, H. Yuki, 
Bull. Chem. Soc. Jpn. 1970, 43, 3195-3198; c) K. Hatada, M. Takeshita, H. Yuki, Tetrahedron Lett. 1968, 9, 46214624.

[11] a) J. Burfeindt, M. Patz, M. Müller, H. Mayr, J. Am. Chem. Soc. 1998, 120, 3629-3634; b) J. Bartl, S. Steenken, H. Mayr, J. Am. Chem. Soc. 1991, 113, 7710-7716.

[12] a) H. C. Brown, P. V. Ramachandran, J. V. N. V. Prasad, J. Org. Chem. 1985, 50, 5583-5586; b) J. Dušek, V. Sklenář, J. Jonas, Collect. Czech. Chem. Commun. 1981, 46, 2912-2923; c) R. Huisgen, L. A. Feiler, P. Otto, Chem. Ber. 1969, 102, 3405-3427.

[13] J. P. Richard, T. L. Amyes, K. B. Williams, Pure Appl. Chem. 1998, 70, 2007-2014.

[14] M. Lou, M. E. Gilpin, S. K. Burger, A. M. Malik, V. Gawuga, V. Popović, A. Capretta, P. J. Berti, J. Am. Chem. Soc. 2012, 134, 12947-12957.

[15] A. Kanazawa, S. Kanaoka, S. Aoshima, Chem. Lett. 2010, 39, 1232-1237.

[16] P. G. M. Wuts, Greene's protective groups in organic synthesis, John Wiley \& Sons, Hoboken, New Jersey, 2014.

[17] R. G. Powell, R. V. Madrigal, C. R. Smith, K. L. Mikolajczak, J. Org. Chem. 1974, 39, 676-680.

[18] W.-D. Z. Li, Z.-H. Gao, Org. Lett. 2005, 7, 29172920 .

[19] C. Olier, M. Kaafarani, S. Gastaldi, M. P. Bertrand, Tetrahedron 2010, 66, 413-445.

[20] C. Nussbaumer, G. Fráter, J. Org. Chem. 1987, 52, 2096-2098.

[21] C. Nussbaumer, G. Fráter, Helv. Chim. Acta 1987, 70, 396-401.

[22] B. Maurer, A. Grieder, W. Thommen, Helv. Chim. Acta 1979, 62, 44-47.

[23] S. A. Kozmin, Org. Lett. 2001, 3, 755-758.

[24] D. J. Hart, C. E. Bennett, Org. Lett. 2003, 5, 14991502 .

[25] Y. Yang, P. Jia, S. Liu, W. Yu, Chin. J. Chem. 2012, 30, 1439-1444.

[26] G. Fráter, U. Müller, P. Kraft, Helv. Chim. Acta 2004, $87,2750-2763$.

[27] D. J. Hart, C. E. Bennett, R. Figueroa, D. Yang, Heterocycles 2006, 70, 119.

[28] S. Sultana, K. Indukuri, M. J. Deka, A. K. Saikia, J. Org. Chem. 2013, 78, 12182-12188.

[29] a) M. S. Kwon, S. K. Woo, S. W. Na, E. Lee, Angew. Chem. 2008, 47, 1733-1735; b) P. T. Seden, J. P. H. Charmant, C. L. Willis, Org. Lett. 2008, 10, 1637-1640; c) J. Yadav, B. Padmavani, B. V. Reddy, C. Venugopal, A. Rao, Synlett 2007, 2045-2048; d) C. S. Barry, N. Bushby, J. P. H. Charmant, J. D. Elsworth, J. R. Harding, C. L. Willis, Chem. Commun. 2005, 5097-5099; e) C. S. Barry, N. Bushby, J. R. Harding, C. L. Willis, Org. Lett. 2005, 7, 2683-2686.
[30] A. Puglisi, A.-L. Lee, R. R. Schrock, A. H. Hoveyda, Org. Lett. 2006, 8, 1871-1874.

[31] P. Gogoi, V. K. Das, A. K. Saikia, J. Org. Chem. 2014, 79, 8592-8598.

[32] D. J. Kopecky, S. D. Rychnovsky, J. Am. Chem. Soc. 2001, 123, 8420-8421.

[33] J. A. Faunce, B. A. Grisso, P. B. Mackenzie, J. Am. Chem. Soc. 1991, 113, 3418-3426.

[34] B. Patterson, S. Marumoto, S. D. Rychnovsky, Org. Lett. 2003, 5, 3163-3166.

[35] M. L. Bolla, B. Patterson, S. D. Rychnovsky, J. Am. Chem. Soc. 2005, 127, 16044-16045.

[36] a) L. L. Cheung, S. Marumoto, C. D. Anderson, S. D. Rychnovsky, Org. Lett. 2008, 10, 3101-3104; b) L. J. van Orden, B. D. Patterson, S. D. Rychnovsky, J. Org. Chem. 2007, 72, 5784-5793.

[37] P. Ondet, A. Joffrin, I. Diaf, G. Lemière, E. Duñach, Org. Lett. 2015, 17, 1002-1005.

[38] P. Ondet, L. Lempenauer, E. Duñach, G. Lemière, Org. Chem. Front. 2016, 3, 999-1003.

[39] G. Stork, A. W. Burgstahler, J. Am. Chem. Soc. 1955, 77, 5068-5077.

[40] a) J. A. Feducia, M. R. Gagné, J. Am. Chem. Soc. 2008, 130, 592-599; b) A. Fürstner, L. Morency, Angew. Chem. Int. Ed. 2008, 47, 5030-5033; c) R. A. Yoder, J. N. Johnston, Chem. Rev. 2005, 105, 4730-4756.

[41] M. Murai, N. Hosokawa, D. Roy, K. Takai, Org. Lett. 2014, 16, 4134-4137.

[42] a) D. Xu, T. M. Penning, I. A. Blair, R. G. Harvey, J. Org. Chem. 2009, 74, 597-604; b) R. G. Harvey, K. Lim, Q. Dai, J. Org. Chem. 2004, 69, 1372-1373; c) R. G. Harvey, Q. Dai, C. Ran, T. M. Penning, J. Org. Chem. 2004, 69, 2024-2032.

[43] a) M. Méndez, M. P. Muñoz, C. Nevado, D. J. Cárdenas, A. M. Echavarren, J. Am. Chem. Soc. 2001, 123, 10511-10520; b) M. Méndez, M. P. Muñoz, A. M. Echavarren, J. Am. Chem. Soc. 2000, 122, 11549-11550.

[44] C. Nevado, D. J. Cárdenas, A. M. Echavarren, Chem. Eur. J. 2003, 9, 2627-2635.

[45] C. Nieto-Oberhuber, M. P. Muñoz, S. López, E. Jiménez-Núñez, C. Nevado, E. Herrero-Gómez, M. Raducan, A. M. Echavarren, Chem. Eur. J. 2006, 12, 1677-1693.

[46] R. Dorel, P. R. McGonigal, A. M. Echavarren, Angew. Chem. Int. Ed. 2016, 55, 11120-11123.

[47] C. Nevado, C. Ferrer, A. M. Echavarren, Org. Lett. 2004, 6, 3191-3194.

[48] C. Nevado, L. Charruault, V. Michelet, C. NietoOberhuber, M. P. Muñoz, M. Méndez, M.-N. Rager, J.-P. Genêt, A. M. Echavarren, Eur. J. Org. Chem. 2003, 706713.

[49] A. S. Kende, D. J. Wustrow, Tetrahedron Lett. 1985, 26, 5411-5414. 
[50] Pericyclic Reactions. M. B. East in Handbook of chiral chemicals, (Ed.: D. J. Ager), Taylor \& Francis, Boca Raton, Florida, 2006, pp. 503-529.

[51] C. E. Sleet, U. K. Tambar, P. Maity, Tetrahedron 2017, 73, 4023-4038.

[52] a) P. Kočovský, F. Tureček, J. Hájíček, Synthesis of natural products. Problems of stereoselectivity, CRC Press, Boca Raton, Florida, 1986; b) G. Desimoni, Tacconi, G., Barco, A., G. P. Polinni, Natural products synthesis through pericyclic reactions, American Chemical Society, Washington, D.C., 1983.

[53] a) Z. M. Png, H. Zeng, Q. Ye, J. Xu, Chem. Asian J. 2017, 12, 2142-2159; b) X. Jiang, R. Wang, Chem. Rev. 2013, 113, 5515-5546; c) L. Fisera, B. Dugovic, C. Hametner, T. Wiesenganger, N. Prónayová, Heterocycles 2005, 65, 591; d) P. Müller, S. Chappellet, Helv. Chim. Acta 2005, 88, 1010-1021; e) D. L. Boger, Chemtracts 1996, 9, 149-189; f) S. E. Denmark, A. Thorarensen, Chem. Rev. 1996, 96, 137-166; g) R. Huisgen, L. Möbius, G. Szeimies, Chem. Ber. 1965, 98, 1138-1152.

[54] a) J. Rehbein, M. Hiersemann, Synthesis 2013, 45, 1121-1159; b) E. A. Ilardi, C. E. Stivala, A. Zakarian, Chem. Soc. Rev. 2009, 38, 3133-3148; c) U. Nubbemeyer, Synthesis 2003, 7, 961-1008.

[55] a) M. H. Suhre, M. Reif, S. F. Kirsch, Org. Lett. 2005, 7, 3925-3927; b) A. G. M. Barrett, M. Ahmed, S. P. Baker, S. P. D. Baugh, D. C. Braddock, P. A. Procopiou, A. J. P. White, D. J. Williams, J. Org. Chem. 2000, 65, 3716-3721. [56] L. F. Tietze, H. Denzer, X. Holdgrün, M. Neumann, Angew. Chem. 1987, 99, 1309-1310.

[57] K. C. Nicolaou, Gray, D. L. F., J. Tae, Angew. Chem. Int. Ed. 2001, 40, 3675-3678.

[58] J.-P. Lumb, K. C. Choong, D. Trauner, J. Am. Chem. Soc. 2008, 130, 9230-9231.

[59] S. E. Denmark, M. S. Dappen, J. A. Sternberg, J. Org. Chem. 1984, 49, 4741-4743.

[60] a) S. E. Denmark, L. Gomez, J. Org. Chem. 2003, 68, 8015-8024; b) S. E. Denmark, L. Gomez, Org. Lett. 2001, 3, 2907-2910.

[61] S. E. Denmark, R. Y. Baiazitov, J. Org. Chem. 2006, $71,593-605$.

[62] S. Torrente, B. Noya, V. Branchadell, R. Alonso, J. Org. Chem. 2003, 68, 4772-4783.

[63] a) N. Jana, T. G. Driver, Org. Biomol. Chem. 2015, 13,9720-9741; b) N. S. Sheikh, Org. Biomol. Chem. 2015, 13, 10774-10796; c) S. Thompson, A. G. Coyne, P. C. Knipe, M. D. Smith, Chem. Soc. Rev. 2011, 40, 42174231; d) C. M. Beaudry, J. P. Malerich, D. Trauner, Chem. Rev. 2005, 105, 4757-4778.

[64] B. Dinda, Essentials of pericyclic and photochemical reactions, Springer International Publishing Switzerland, 2017.

[65] a) R. B. Woodward, R. Hoffmann, Angew. Chem. Int. Ed. Engl. 1969, 8, 781-853; b) R. B. Woodward, R. Hoffmann, J. Am. Chem. Soc. 1965, 87, 395-397.
[66] a) M. J. Di Grandi, Org. Biomol. Chem. 2014, 12, 5331-5345; b) W. T. Spencer, T. Vaidya, A. J. Frontier, Eur. J. Org. Chem. 2013, 2013, 3621-3633; c) T. Vaidya, R. Eisenberg, A. J. Frontier, ChemCatChem 2011, 3, 1531-1548; d) T. N. Grant, C. J. Rieder, F. G. West, Chem. Commun. 2009, 5676-5688; e) M. A. Tius, Eur. J. Org. Chem. 2005, 2193-2206; f) A. J. Frontier, C. Collison, Tetrahedron 2005, 61, 7577-7606; g) H. Pellissier, Tetrahedron 2005, 61, 6479-6517.

[67] S. Casson, P. Kocieński, J. Chem. Soc., Perkin Trans. 1 1994, 1187-1191.

[68] S.-H. Kim, J. K. Cha, Synthesis 2000, 2113-2116.

[69] H. Muxfeldt, M. Weigele, V. van Rheenen, J. Org. Chem. 1965, 30, 3573-3574.

[70] D. Trauner, S. N. Gradl, G. Liang, Org. Lett. 2003, 5, 4931-4934.

[71] a) W. He, I. R. Herrick, T. A. Atesin, P. A. Caruana, C. A. Kellenberger, A. J. Frontier, J. Am. Chem. Soc. 2008, 130, 1003-1011; b) W. He, X. Sun, A. J. Frontier, J. Am. Chem. Soc. 2003, 125, 14278-14279.

[72] M. Janka, W. He, I. E. Haedicke, F. R. Fronczek, A. J. Frontier, R. Eisenberg, J. Am. Chem. Soc. 2006, 128, 5312-5313.

[73] C. Bee, M. A. Tius, Org. Lett. 2003, 5, 1681-1684.

[74] M. E. Krafft, D. V. Vidhani, J. W. Cran, M. Manoharan, Chem. Commun. 2011, 47, 6707-6709.

[75] a) P. A. Wender, R. T. Stemmler, L. E. Sirois, J. Am. Chem. Soc. 2010, 132, 2532-2533; b) L. Bartali, P. Larini, A. Guarna, E. Occhiato, Synthesis 2007, 1733-1737.

[76] K. Murugan, S. Srimurugan, C. Chen, Chem. Commun. 2010, 46, 1127-1129.

[77] a) M. Barbero, S. Cadamuro, A. Deagostino, S. Dughera, P. Larini, E. Occhiato, C. Prandi, S. Tabasso, R. Vulcano, P. Venturello, Synthesis 2009, 2260-2266; b) M. Amere, J. Blanchet, M.-C. Lasne, J. Rouden, Tetrahedron Lett. 2008, 49, 2541-2545.

[78] F. Douelle, L. Tal, M. F. Greaney, Chem. Commun. 2005, 660-661.

[79] G. Liang, D. Trauner, J. Am. Chem. Soc. 2004, 126, 9544-9545.

[80] a) S. Raja, W. Ieawsuwan, V. Korotkov, M. Rueping, Chem. Asian J. 2012, 7, 2361-2366; b) M. Rueping, W. Ieawsuwan, Chem. Commun. 2011, 47, 11450-11452; c) M. Rueping, W. Ieawsuwan, Adv. Synth. Catal. 2009, 351, 78-84; d) M. Rueping, W. Ieawsuwan, A. P. Antonchick, B. J. Nachtsheim, Angew. Chem. Int. Ed. 2007, 46, 20972100 .

[81] a) G. E. Hutson, Y. E. Türkmen, V. H. Rawal, J. Am. Chem. Soc. 2013, 135, 4988-4991; b) D. J. Kerr, B. L. Flynn, Org. Lett. 2012, 14, 1740-1743; c) P. Cao, C. Deng, Y.-Y. Zhou, X.-L. Sun, J.-C. Zheng, Z. Xie, Y. Tang, Angew. Chem. Int. Ed. 2010, 49, 4463-4466.

[82] a) A. Deagostino, M. Migliardi, E. G. Occhiato, C. Prandi, C. Zavattaro, P. Venturello, Tetrahedron 2005, 61, 
3429-3436; b) C. Prandi, A. Ferrali, A. Guarna, P. Venturello, E. G. Occhiato, J. Org. Chem. 2004, 69, 77057709; c) E. G. Occhiato, C. Prandi, A. Ferrali, A. Guarna, P. Venturello, J. Org. Chem. 2003, 68, 9728-9741; d) E. G. Occhiato, C. Prandi, A. Ferrali, A. Guarna, A. Deagostino, P. Venturello, J. Org. Chem. 2002, 67, 7144-7146.

[83] a) C. Prandi, E. G. Occhiato, S. Tabasso, P. Bonfante, M. Novero, D. Scarpi, M. E. Bova, I. Miletto, Eur. J. Org. Chem. 2011, 2011, 3781-3793; b) C. Bhattacharya, P. Bonfante, A. Deagostino, Y. Kapulnik, P. Larini, E. G. Occhiato, C. Prandi, P. Venturello, Org. Biomol. Chem. 2009, 7, 3413-3420.

[84] C. Prandi, A. Deagostino, P. Venturello, E. G. Occhiato, Org. Lett. 2005, 7, 4345-4348.

[85] J. Barluenga, P. Barrio, R. Vicente, L. A. López, M. Tomás, J. Organomet. Chem. 2004, 689, 3793-3799.

[86] M. A. Tius, Chem. Soc. Rev. 2014, 43, 2979-3002.

[87] P. E. Harrington, L. Li, M. A. Tius, J. Org. Chem. 1999, 64, 4025-4029.
[88] L. Lempenauer, E. Duñach, G. Lemière, Org. Lett. 2016, 18, 1326-1329.

[89] M. Kokubo, S. Kobayashi, Chem. Asian J. 2009, 4, $526-528$.

[90] a) F. De Simone, T. Saget, F. Benfatti, S. Almeida, J. Waser, Chem. Eur. J. 2011, 17, 14527-14538; b) F. de Simone, J. Andrès, R. Torosantucci, J. Waser, Org. Lett. 2009, 11, 1023-1026.

[91] D. V. Patil, L. H. Phun, S. France, Org. Lett. 2010, 12, 5684-5687.

[92] M. Shindo, K. Yaji, T. Kita, K. Shishido, Synlett 2007, 1096-1100.

[93] a) K. Yaji, M. Shindo, Tetrahedron Lett. 2010, 51, 5469-5472; b) K. Yaji, M. Shindo, Tetrahedron 2010, 66, 9808-9813.

[94] K. Yaji, M. Shindo, Synlett 2009, 2524-2528. 


\section{REVIEW}

This review summarises the state of the art in the field of intramolecular cyclisation reactions of precursors bearing an enol ether function as a reactive moiety. Special attention is given to Lewis or Brønsted acid-catalysed processes following carbocationic-type cyclisation mechanisms

Adv. Synth. Catal. Year, Volume, Page - Page

Luisa Lempenauer, Gilles Lemière*, Elisabet Duñach*

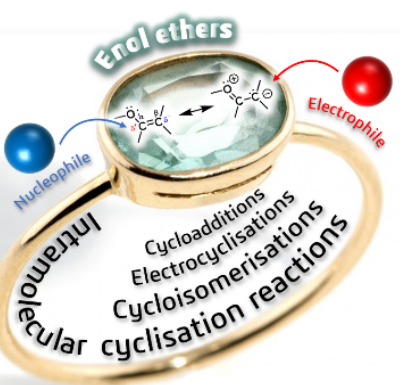

